ARTICLE

\title{
Visualising G-quadruplex DNA dynamics in live cells by fluorescence lifetime imaging microscopy
}

Peter A. Summers (1) 1,8, Benjamin W. Lewis ${ }^{1,2,3,4,8}$, Jorge Gonzalez-Garcia (1) 1,7, Rosa M. Porreca 2,3, Aaron H. M. Lim,4, Paolo Cadinu1, Nerea Martin-Pintado5 , David J. Mann ${ }^{6}$, Joshua B. Edel (1) 1, Jean Baptiste Vannier (1) ${ }^{2,3 凶}$, Marina K. Kuimova (i) ${ }^{1,4 凶}$ \& Ramon Vilar (i) ${ }^{1,4 凶}$

Guanine rich regions of oligonucleotides fold into quadruple-stranded structures called G-quadruplexes (G4s). Increasing evidence suggests that these G4 structures form in vivo and play a crucial role in cellular processes. However, their direct observation in live cells remains a challenge. Here we demonstrate that a fluorescent probe (DAOTA-M2) in conjunction with fluorescence lifetime imaging microscopy (FLIM) can identify G4s within nuclei of live and fixed cells. We present a FLIM-based cellular assay to study the interaction of nonfluorescent small molecules with G4s and apply it to a wide range of drug candidates. We also demonstrate that DAOTA-M2 can be used to study G4 stability in live cells. Reduction of FancJ and RTEL1 expression in mammalian cells increases the DAOTA-M2 lifetime and therefore suggests an increased number of G4s in these cells, implying that FancJ and RTEL1 play a role in resolving $\mathrm{G} 4$ structures in cellulo.

\footnotetext{
${ }^{1}$ Department of Chemistry, Molecular Sciencess Research Hub, White City Campus, Imperial College London, London W12 OBZ, UK. ${ }^{2}$ Telomere Replication and Stability group, Medical Research Council - London Institute of Medical Sciences, London W12 ONN, UK. ${ }^{3}$ Institute of Clinical Sciences, Faculty of Medicine, Imperial College London, London W12 ONN, UK. ${ }^{4}$ Institute of Chemical Biology, Imperial College London, London W12 BZ, UK. ${ }^{5}$ Oncode Institute, Hubrecht Institute-KNAW and University Medical Center Utrecht, Utrecht, The Netherlands. ${ }^{6}$ Department of Life Sciences, Imperial College London South Kensington, London SW7 2AZ, UK. ${ }^{7}$ Present address: Department of Inorganic Chemistry, University of Valencia, Jose Beltran 2, Paterna 46980, Spain. ${ }^{8}$ These authors contributed equally: Peter A. Summers, Benjamin W. Lewis. ${ }^{\circledR}$ email: j.vannier@imperial.ac.uk; m.kuimova@imperial.ac.uk; r.vilar@imperial.ac.uk
} 
G uanine-rich sequences of DNA can fold into tetrastranded helical assemblies known as G-quadruplexes (G4s). These structures are implicated in a number of essential biological processes such as telomere maintenance, transcription, translation, and replication ${ }^{1-4}$. A series of bioinformatical studies initially suggested that there are over 350,000 putative G4-forming sequences in the human genome $e^{5,6}$, with subsequent studies reporting an even larger number ${ }^{7}$. Following these predictions, sequencing studies using purified human genomic DNA revealed over 700,000 sequences that form G4 structures under in vitro conditions ${ }^{8}$. More recently, the prevalence of G4s in human chromatin has been investigated using an immunoprecipitation technique ${ }^{9,10}$. These studies showed that there are over 10,000 sequences in the human genome that can form G4 DNA structures under cellular conditions 9 . Interestingly, these G4 structures are mainly located in gene promoter regions and in $5^{\prime}$-untranslated regions (5'-UTR) of genes supporting the proposed hypothesis that G4 DNA is involved in a number of essential biological regulatory processes.

While the exact roles that G4 structures play in biology are still under significant scrutiny, it is commonly accepted that G4 formation can be detrimental to certain biological processes and can lead to DNA damage ${ }^{11,12}$. Therefore, it is not surprising that several helicases such as Pifl, RecQ, RTEL1, FancJ, and BLM have been found to unfold G4 structures in vitro ${ }^{13}$. While it is known that G4 DNA helicases are important in maintaining genome integrity in cells, the direct link between their in vitro G4 unwinding activity and genome instability associated with their mutations is still missing.

Considering the wide range of biological processes associated with G4s, there has been significant interest in developing tools to detect and visualise G4 DNA structures in cells. With widespread application in immunofluorescent staining, high-affinity antibodies have been developed to visualise G4 in cells ${ }^{14-19}$. An early antibody found to be selective against telomeric G4 showed nuclear staining in the ciliate Stylonychia lemnae ${ }^{15}$. Subsequent studies have reported high-affinity antibodies able to visualise G4 DNA and G4 RNA in mammalian cells by immunofluorescent staining ${ }^{16-18}$. While these elegant studies are the most direct evidence of the presence of G4s in cells, they have some potential drawbacks. The fixation process can denature the cellular DNA and induce DNA degradation ${ }^{20,21}$, and the high affinity of the antibodies for G4 could artificially increase the presence of G4 structures. Furthermore, antibodies are not suitable for use in live cells and hence cannot be used to study G4 dynamics in real time.

These limitations can be overcome by using small-molecule optical probes ${ }^{22-24}$. Most G4 DNA optical probes reported to date rely on a large enhancement in emission intensity upon binding G4 ('switch-on'), compared to binding duplex (ds) $\mathrm{DNA}^{24}$. For example, Thioflavin T (ThT) and its derivatives have shown to be switch-on probes for G4s, with up to 150 -fold fluorescence enhancement vs. dsDNA (under optimal conditions) and have been used for live cell imaging of both DNA and RNA $\mathrm{G}^{2} \mathrm{~s}^{25-27}$. However, ThT is known to bind to other biologically relevant molecules (e.g. protein aggregates ${ }^{28}$ ) and is highly sensitive to the matrix microviscosity ${ }^{29}$, potentially triggering nonG4 emission. While these small-molecule probes provide a good way of studying G4s in cell-free environments, their emission intensity is concentration dependent. In the vast excess of nuclear dsDNA (and other biomolecules), distinguishing G4 foci from background emission is challenging, even with a very high switchon ability. Additionally, extracting quantitative information from emission intensity alone is difficult, since the cellular concentrations of neither the probe nor G4s are known. More complex approaches are required to gain insight in cellulo, such as the recently reported study using single-molecule fluorescence imaging for G4 detection ${ }^{30}$.

An alternative approach is to use a change in the fluorescence lifetime (a concentration-independent parameter) of a probe upon binding to different DNA structures ${ }^{31-35}$. For example, the fluorescence lifetime of 3,6-bis(1-methyl-2-vinyl-pyridinium) carbazole diiodide (o-BMVC) is longer when bound to G4 (ca. $2.5 \mathrm{~ns}$ ) than non-G4 DNA sequences (ca. $1.5 \mathrm{~ns}$ ). This difference was used to identify long lifetime foci in both the nucleus and cytoplasm of mammalian cells, however, this dye is only permeable to fixed cells and so no dynamic live cell work was possible ${ }^{33,34}$. More recently, a fluorescence lifetime-based probe (a tripodal cationic fluorescent molecule, NBTE) was reported that can distinguish G4 (3-4 ns) and dsDNA (2.0-2.5 ns) in live cells $^{35}$. We previously reported that DAOTA-M2 [Fig. 1a] has a very different fluorescence lifetime when bound to G4 structures as compared to duplex or single-stranded DNA, with good live cell permeability and low cytotoxicity ${ }^{32}$. Herein we show that DAOTA-M2 can be used to visualise dynamic processes involving G4s in live cells. We confirm that while the probe works in fixed cells, there are differences in G4 abundance, highlighting the importance of carrying out G4 imaging experiments in live, rather than fixed environments. We demonstrate that DAOTA-M2 responds to the expression of DNA helicases FancJ and RTEL1 which are involved in genome stability and the distribution of G4 in live cells. Finally, we present a quantitative fluorescence lifetime-based assay to visualise the interaction of small molecules (which are not fluorescent themselves) with G4 structures in live cells.

\section{Results}

Biophysical characterisation of DAOTA-M2 interacting with DNA. Previously, we have shown that DAOTA-M2 is a medium-strength DNA binder ${ }^{36}$, with a moderately greater affinity for $\mathrm{G} 4$ over dsDNA $\left(\mathrm{K}_{\mathrm{d}}=\mathrm{ca} .1 .7 \mu \mathrm{M}\right.$ for dsDNA and ca. $1.0 \mu \mathrm{M}$ for $\mathrm{G} 4)^{32,37}$. Despite similar binding affinities, the intensity-weighted average lifetime $\left(\tau_{\mathrm{w}}\right)$ upon binding is found to be dependent on the DNA topology. These values range from ca. 5-7 ns when bound to dsDNA, ca. 7-11 ns when bound to RNA and ca. 9-12 ns when bound to G4 DNA [Fig. 1b, c] and are independent of absolute concentration [Supplementary Fig. 1a]. Given the complex excited state decay of DAOTA-M2, we have now optimised our fitting algorithm and have chosen to use $\tau_{\mathrm{w}}$ as a reporter instead of $\tau_{2}$ as used previously, due to a more straightforward and accurate fitting of fluorescence lifetime imaging data (vide infra) ${ }^{30}$.

To establish the effect of proteins, lipids, carbohydrates and biomolecules other than nucleic acids on the lifetime of DAOTAM2, we used a highly protein-concentrated and nucleic aciddepleted Xenopus egg extract ${ }^{38} . \tau_{\mathrm{w}}$ increases from $2.5 \pm 0.3 \mathrm{~ns}$ in aqueous buffer to $7.3 \pm 0.3 \mathrm{~ns}$ in cell extract [Fig. 1d], indicating an effect from other biomolecules on the fluorescence lifetime. Reassuringly, $\tau_{\mathrm{w}}$ increases to $10.8 \pm 0.6 \mathrm{~ns}$ on addition of G4 to the extract, and decreases to $6.1 \pm 0.3 \mathrm{~ns}$ with dsDNA, consistent with the results observed in aqueous buffered solutions [Fig. 1c]. This result implies a higher affinity of DAOTA-M2 for DNA over other cellular biomolecules. In a nuclear environment, given the vast excess of nucleic acid, DAOTA-M2 should preferentially bind to DNA and the lifetime will give an indication of the DNA topology.

We next set out to examine whether the DAOTA-M2 lifetime can report on competitive interactions of other binders to G4 in vitro. Due to a higher affinity for quadruplexes, addition of G4 to a mixture of DAOTA-M2 and dsDNA increases the lifetime from $6.1 \pm 0.2 \mathrm{~ns}$ [Fig. 1e, green trace] to $11.7 \pm 0.4 \mathrm{~ns}$ [Fig. 1e, red trace]. 


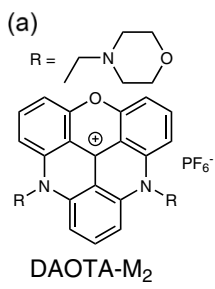

DAOTA-M $\mathrm{M}_{2}$<smiles>NCCOc1cc(NC(=O)c2cc(OCCN)c3ccccc3n2)nc(C(=O)Nc2cc(OCCN)c3ccccc3n2)c1</smiles>

PDS

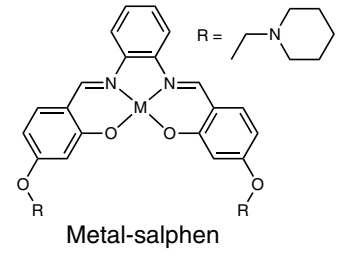

$\mathrm{M}=\mathrm{Zn}, \mathrm{Cu}, \mathrm{VO}, \mathrm{Ni}$

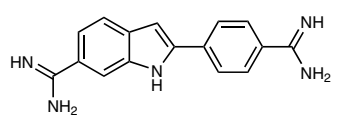

DAPI
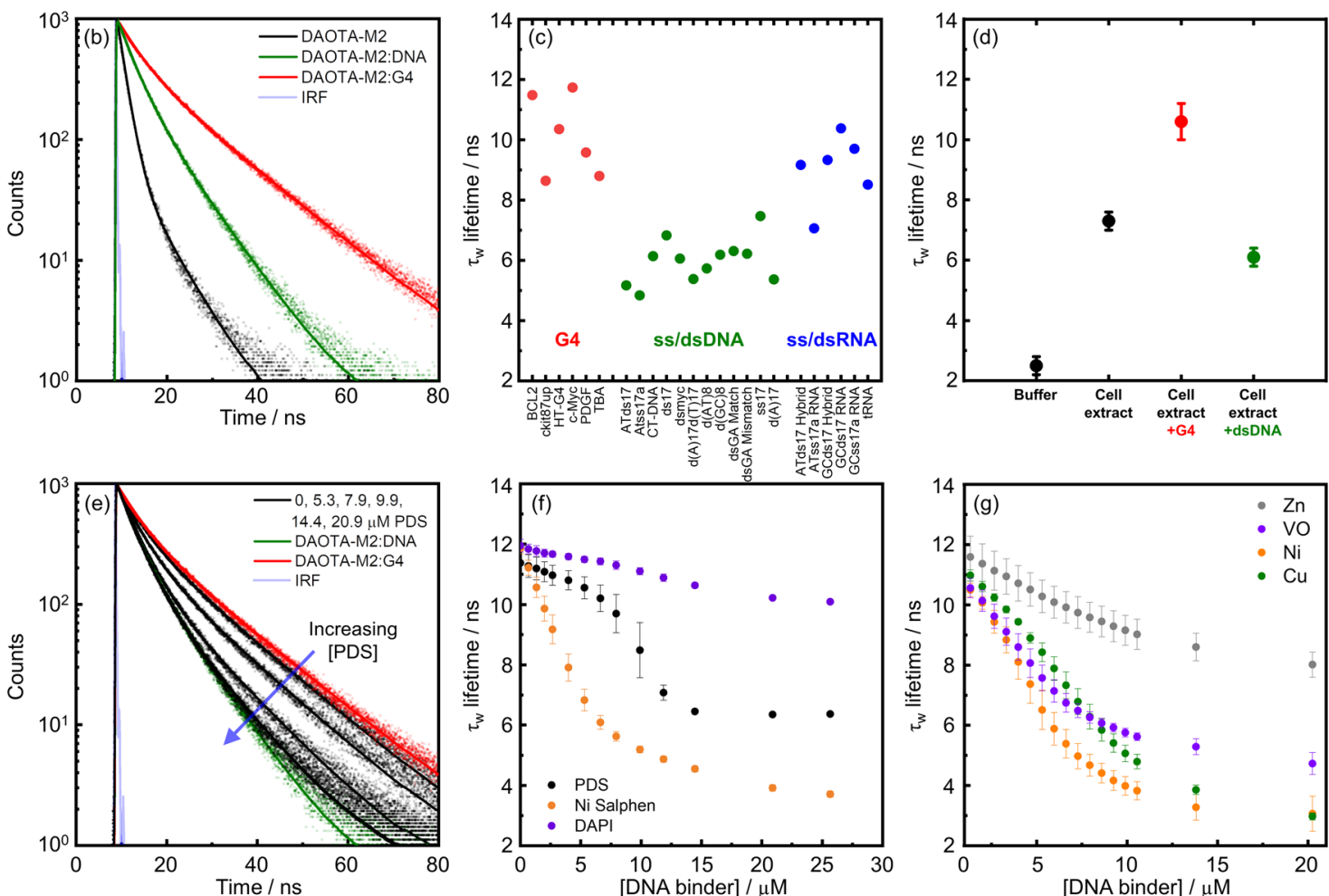

Fig. 1 In vitro fluorescence-lifetime of DAOTA-M2 bound to different DNA topologies. a Chemical structures of the DNA binders under study in this work. b Time-resolved fluorescence decays of DAOTA-M2 $(2 \mu \mathrm{M}$, black trace) and following the subsequent additions of dsDNA (CT-DNA, $20 \mu \mathrm{M}$, green trace) and then $\mathrm{G} 4$ (c-Myc, $4 \mu \mathrm{M}$, red trace). Instrument response function (IRF) is shown in grey. Recorded data is shown as dots and fitted biexponential function as a solid line. $\mathbf{c}$ Variation of the average lifetime ( $\left.\tau_{\mathrm{w}}\right)$ of DAOTA-M2 in the presence of different G4s (red dots), ss/dsDNA (green dots) and ss/ dsRNA (blue dots), adapted from reference ${ }^{32}$. d Fluorescence-lifetimes of DAOTA-M2 ( $\left.2 \mu \mathrm{M}\right)$ in aqueous buffer (black dot), buffered Xenopus egg extract ( $33 \mu \mathrm{L}$ egg extract $+12 \mu \mathrm{L}$ aqueous buffer, black dot), and in buffered cell extract supplemented with G4 ( $4 \mu \mathrm{M} \mathrm{c}-\mathrm{Myc}$, red dot) and dsDNA (44 $\mu \mathrm{M}$ ds 26 , green dot). Both measurements remained constant over $0.5 \mathrm{hr}$ incubation at $21^{\circ} \mathrm{C}$. Mean value from 3 independent measurements, error bars represent standard deviation. e In a mixture of DAOTA-M2 ( $2 \mu \mathrm{M})$, dsDNA (CT-DNA, $20 \mu \mathrm{M})$, and G4 (c-Myc, $4 \mu \mathrm{M})$, increasing amounts of PDS (5.3. 7.9. 9.9, and 14.4 $\mu \mathrm{M}$, black traces) displaces DAOTA-M2 from a G4 to dsDNA environment. Recorded data is shown as dots and fitted biexponential function as a solid line. $\mathbf{f}$ Variation of $\tau_{\mathrm{w}}$ in a mixture of DAOTA-M2 $(2 \mu \mathrm{M})$, dsDNA (CT-DNA, $\left.20 \mu \mathrm{M}\right)$, and G4 (c-Myc, $\left.4 \mu \mathrm{M}\right)$, with increasing concentrations of G4 binders PDS (black dots) and Ni-salphen (orange dots), and a non-G4 binder DAPI (purple dots). See Figure S2 for example decays. Mean value from 3 independent measurements, error bars represent standard deviation. $\mathbf{g}$ Variation of $\tau_{\mathrm{w}}$ in a mixture of DAOTA-M2 (2 $\mu$ M) and G4 (c-Myc, $\left.4 \mu M\right)$, with increasing concentrations of $\mathrm{Zn}$ (grey dots), VO (purple dots), Ni (orange dots), and Cu (green dots)-salphens. Mean value from 3 independent measurements, error bars represent standard deviation. Unless stated otherwise, all experiments in $10 \mathrm{mM}$ lithium cacodylate buffer (pH 7.3) with $100 \mathrm{mM}$ $\mathrm{KCl}$. Source Data are available as a Source Data file for Fig. 1b-g.

The subsequent addition of pyridostatin (PDS), a selective G4 binder with a greater affinity for G4 than DAOTA-M2 $\left(\mathrm{K}_{\mathrm{d}}=\mathrm{ca}\right.$. $0.5^{39,40}$ and ca. $1.0 \mu \mathrm{M}^{32}$, respectively) ${ }^{41}$, displaces DAOTA-M2 from $\mathrm{G} 4$ back to dsDNA, accompanied by a drop in $\tau_{\mathrm{w}}$ [Fig. 1f, black dots]. When the experiment is repeated using DAPI, which is a well-established dsDNA minor groove binder ${ }^{42}$ and non-G4 binder, only a small drop in $\tau_{\mathrm{w}}$ is observed as DAOTA-M2 stays bound to G4 [Fig. 1f]. The dynamic equilibrium between dsDNA and G4 bound DAOTA-M2 can also be disrupted through the addition of a large excess of dsDNA into a solution of G4 and DAOTA-M2 [Supplementary Fig. 1b].
We then investigated DAOTA-M2 displacement using $\mathrm{Ni}$ salphen, another DNA binder which has a higher affinity for both G4 and dsDNA than DAOTA-M2 [Supplementary Fig. 1c] ${ }^{43,44}$. In this case $\tau_{\mathrm{w}}$ drops below the region associated with dsDNA to ca. $3.7 \mathrm{~ns}$, close to that of free dye [Fig. 1f, orange dots]. A range of metal-salphen complexes (with metal $=\mathrm{Ni}, \mathrm{Cu}, \mathrm{VO}, \mathrm{Zn}$ ) are an ideal series to study structurally related molecules with different G4 affinities, as variation in the metal centre changes the metal coordination geometry, which has a dramatic effect on G4 binding: strong $(\mathrm{Ni}, \mathrm{Cu})$, medium $(\mathrm{VO})$ and weak $(\mathrm{Zn})^{45,46}$. Our DAOTA-M2 lifetime-based data [Fig. 1g] confirms a similar 

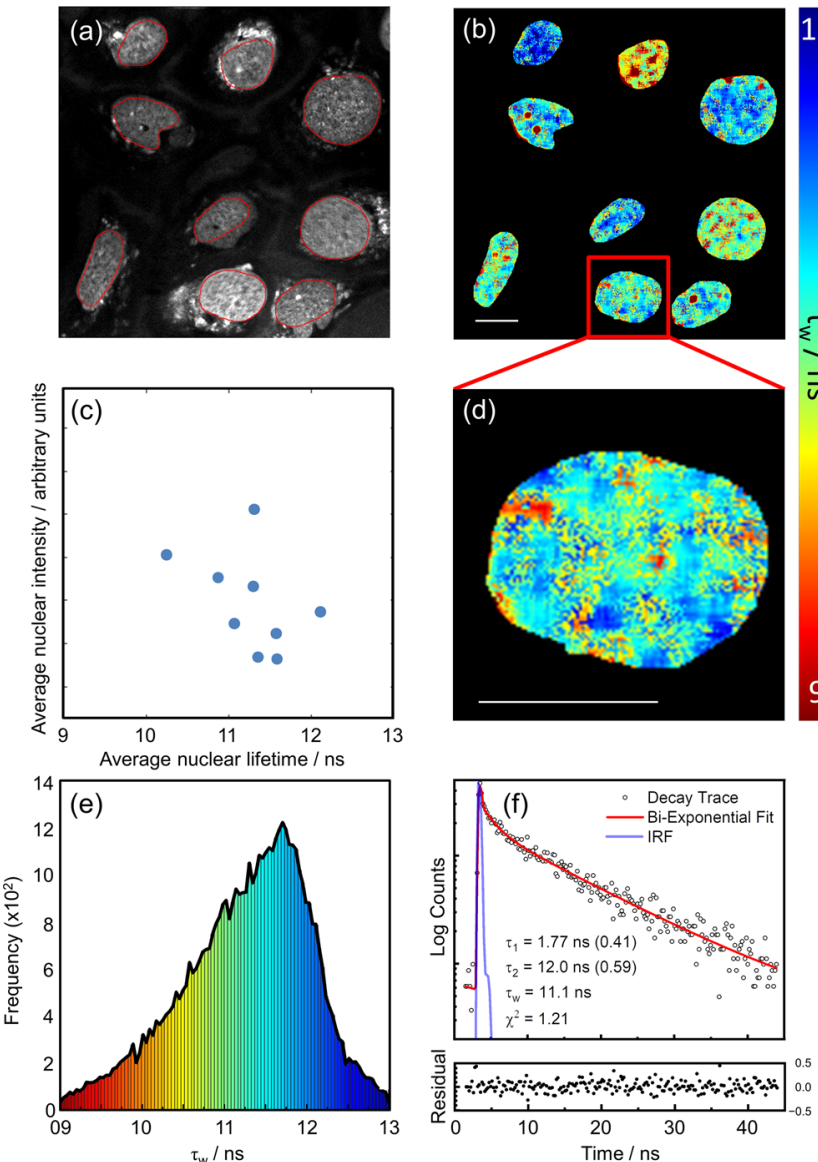

Fig. 2 FLIM analysis of nuclear DNA in live U2OS cells stained with DAOTA-M2 $(20 \mu \mathbf{M}, \mathbf{2 4} \mathbf{h})$. a Fluorescence intensity image recorded at $512 \times 512$ resolution $\left(\lambda_{\text {ex }}=477 \mathrm{~nm}, \lambda_{\text {em }}=550-700 \mathrm{~nm}\right)$, red lines represent the nuclear segmentation used for the FLIM analysis. $\mathbf{b}$ FLIM map from a, displayed between average lifetime $\left(\tau_{w}\right) 9$ (red) and 13 (blue) ns. c 2D correlation of the average nuclear intensity against the average nuclear lifetimes (blue dots). d Zoomed-in FLIM map of a single nucleus - colours represent lifetimes as defined by the colour gradient bar between 9 (red) and 13 (blue) ns. e Histogram of fluorescence lifetime distribution from image shown in $\mathbf{b}$ with the same colour coding. f Fluorescence decay trace (open black dots), fit (red line), and normalised residual (solid black dots) of a representative pixel (including binning) from image shown in $\mathbf{b}$; IRF = Instrumental Response Function plotted as a blue line. Data shown is representative of 13 cells imaged similarly. Scale bars: $20 \mu \mathrm{m}$. Source Data are available as a Source Data file for Fig. 2e, f.

trend, with $\mathrm{Ni}, \mathrm{Cu}$ and VO-salphen complexes displacing DAOTA-M2 more readily than $\mathrm{Zn}$-salphen.

This data indicates that in mixtures of G4 and dsDNA, analysis of the DAOTA-M2 lifetime can accurately differentiate between distinct DNA topologies, thus, we next looked to investigate DAOTA-M2 in live cells using fluorescence lifetime imaging microscopy (FLIM).

Imaging G4s in cellulo using DAOTA-M2 and FLIM. Given the in vitro assay results [Fig. 1] confirming that DAOTA-M2 lifetime can predict the strength of the interaction between small molecule binders and G4s, we set out to use DAOTA-M2 to study the interaction of any molecule with G4s in live cells. Incubation of U2OS cells with DAOTA-M2 $(20 \mu \mathrm{M}, 24 \mathrm{hr})$ results in nuclear staining [Fig. 2a], no obvious changes to cell morphology [Supplementary Fig. 4c], no increased DNA damage response [Supplementary Fig. 4a, b], and some accumulation of cells in S and G2 phases of the cell cycle [Supplementary Fig. 3a, b].

We were able to record FLIM images at high magnification, making it possible to visualise spatial lifetime distributions within the nucleus [Fig. 2d]. Consistent with in vitro experiments, fluorescence decays were fitted to a bi-exponential decay model [Fig. 2f] to obtain the corresponding fluorescence lifetimes $\left(\tau_{\mathrm{w}}\right)$. Figure $2 \mathrm{~b}, \mathrm{~d}$ show resulting FLIM maps; each cell nucleus displays spatially heterogenous lifetime distributions, with areas corresponding to long (12-13 ns, blue) and short (9-10 ns, red) lifetimes. Even at this high resolution, each pixel will contain lifetime information from DAOTA-M2 bound to a large number of duplex and G4 DNA sites which results in a histogram of lifetime distribution within a 10-12 ns range [Fig. 2e and Supplementary Fig. 5g]. Individual nuclear lifetimes [Supplementary Fig. 5h] and average nuclear lifetimes [Fig. 2c] are not correlated with intensity, indicative of the absence of DAOTAM2 self-quenching, which is also consistent with previous in vitro results on the absence of self-quenching up to $100 \mu \mathrm{M}^{32}$. Importantly, increasing dye uptake (and therefore fluorescence intensity) through incubation in starvation conditions results in a minimal change in nuclear lifetimes [Supplementary Fig. 6a], confirming the concentration independence of the FLIM measurement. Furthermore, high intensity of DAOTA-M2 signal within a single nucleus correlates with euchromatin and heterochromatin staining by DAPI [Supplementary Fig. 5c-e], but does not correlate with variations in lifetime [Supplementary Fig. 5h]. This suggests that the lifetime values used to study G4DNA are not modified by local chromatin organisation at a cellular level.

We then employed the same in vitro displacement assay [Fig. 1f] for in cellulo studies using PDS and DAPI. Coincubation with DAOTA-M2 $(20 \mu \mathrm{M})$ and PDS for $24 \mathrm{hr}$ results in very different cellular lifetimes, dropping from $11.4 \pm 1.0 \mathrm{~ns}$ in control cells to $10.3 \pm 1.8 \mathrm{~ns}(5 \mu \mathrm{M}$ PDS $)$ and $9.0 \pm 1.3 \mathrm{~ns}(10 \mu \mathrm{M}$ PDS) [Fig. 3b]. The smaller drop in $\tau_{w}$ with a lower PDS concentration confirms the high concentration of PDS needed to disturb the equilibrium between DAOTA-M2 and G4, seen above in vitro [Fig. 1f]. As a negative control, incubation with DAPI (25, 50 and $90 \mu \mathrm{M}, 1 \mathrm{hr}$ ) led to no change in the average nuclear lifetimes [Fig. 3b and Supplementary Fig. 6b], with nuclear localisation confirmed from the DAPI emission. Based on the consistency of these results with the in vitro characterisation [Fig. 1] and previous cellular work using DAOTA-M2 with $\mathrm{PDS}^{32}$, we propose that the lifetime drop in cellulo is the result of nuclear displacement of DAOTA-M2 from G4.

PDS (as well as many other G4 binders) is known to cause DNA damage, arrest cell growth and activate DNA damage response (DDR) pathways ${ }^{47}$. To establish whether the observed changes in DAOTA-M2's fluorescence lifetime in cells could be due to PDSdependent DNA damage rather than displacement of the probe from G4 structures, we carried out a control experiment with cisplatin. This compound is known to form DNA intra-strand links and activate the apoptotic pathway, but not to bind G4 DNA $^{48}$. Encouragingly, co-incubation of cisplatin with DAOTAM2 did not lead to a decrease in the fluorescence lifetimes recorded by FLIM [Supplementary Fig. 8a]. We also caused DNA damage by inducing double strand breaks with 2 Gy gamma irradiation. Irradiation of cells had no effect $\left(p=7.4 \times 10^{-1}\right)$ on the DAOTA-M2 lifetime [Fig. S8b], confirming that these two types of DNA damage were not the cause of the lifetime decrease observed after incubation of cells with PDS.

FLIM studies using fixed cells. It is common for immunostaining or small molecule staining of G4 in cells to be performed 


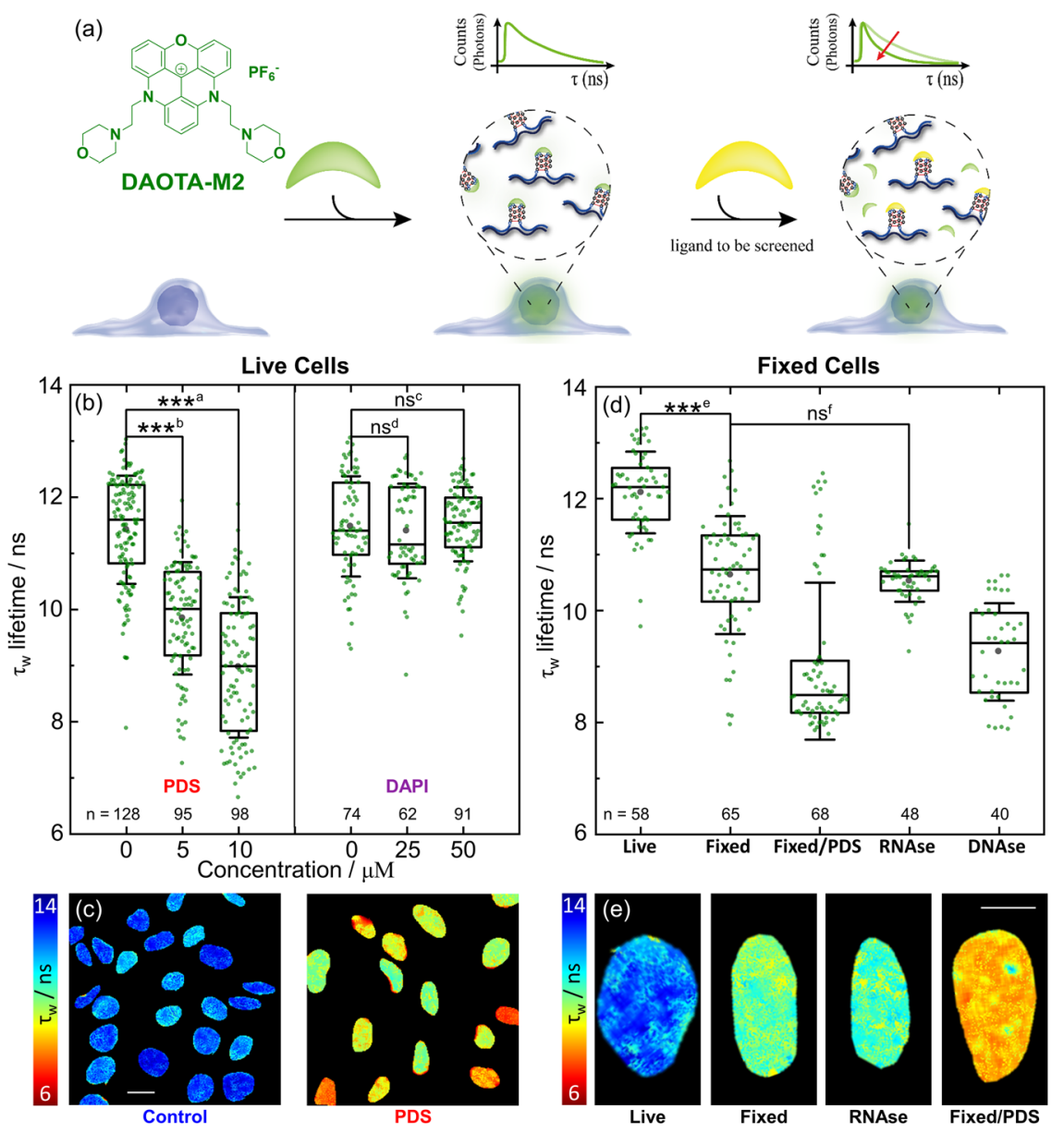

Fig. 3 FLIM analysis of live and fixed U2OS cells using DAOTA-M2. a Schematic representation of the fluorescence lifetime displacement assay. Upon binding of competitors, DAOTA-M2 is displaced from G4 to a dsDNA environment, causing a reduction in its fluorescence lifetime. $\mathbf{b}$ Box plot of mean nuclear lifetimes $\left(\tau_{\mathrm{w}}\right)$ and conditions of co-incubation of DAOTA-M2 $(20 \mu \mathrm{M}, 24-30 \mathrm{~h})$ with PDS $(24 \mathrm{~h})$ and DAPI $(1 \mathrm{~h})$ in live cells. Results from $\mathrm{n}$ cells as stated next to each box, over two independent experiments. c Representative FLIM maps from DAOTA-M2 displayed between 6 (red) and 14 (blue) ns following co-incubation with no additive (Control), and PDS $(10 \mu \mathrm{M}, 24 \mathrm{~h})$ recorded at $256 \times 256$ resolution to speed-up data acquisition without affecting the average lifetime of each nucleus. See Figure S7 for lifetime histograms. Scale bar: $20 \mu \mathrm{m}$. $\mathbf{d}$ Box plot of mean nuclear lifetimes $\left(\tau_{\mathrm{w}}\right)$ after fixation with PFA ( $4 \%$ in PBS) and treatment with PDS $\left(10 \mu \mathrm{M}, 1 \mathrm{hr}\right.$ ), RNAse $\left(1 \mathrm{mg} \mathrm{ml}{ }^{-1}, 10 \mathrm{~min}, 21^{\circ} \mathrm{C}\right.$ ) and DNAse. (200 Units well ${ }^{-1}, 1 \mathrm{~h}, 37^{\circ} \mathrm{C}$ ). Results from $\mathrm{n} \mathrm{cells} \mathrm{as}$ stated next to each box, over two independent experiments. e Representative FLIM maps displayed between 6 (red) and 14 (blue) ns of cells from image shown in (d) recorded at $512 \times 512$ resolution. Scale bar: $10 \mu \mathrm{m}$. Significance: $\mathrm{ns} p>0.05,{ }^{\star} p<0.05,{ }^{\star \star} p<0.01,{ }^{\star \star \star} p<0.001 .{ }^{a} p=1.8 \times 10^{-36}, t=16.1, \mathrm{DF}=$ 177: ${ }^{b} p=8.7 \times 10^{-25}, t=11.8, D F=198:{ }^{c} p=7.6 \times 10^{-1}, t=-0.31, D F=131:{ }^{d} p=5.9 \times 10^{-1}, t=0.54, D F=132:{ }^{e} p=3.2 \times 10^{-15}, t=9.1, D F=114:{ }^{f} p=$ $4.4 \times 10^{-1}, t=0.77, D F=74$. Source Data are available as a Source Data file for Fig. $3 b, d$.

following PFA fixation (needed for permeabilising the cellular membrane), which crosslinks proteins, increases cell rigidity and chemically alters the cell morphology. This process is known to impact nucleic acids within the cell, denaturing DNA and causing DNA damage ${ }^{20,21}$. However, DNAse and RNAse treatment is possible in fixed cells, and allows for examination of the effect of nuclear RNA on the DAOTA-M2 lifetime. This is an important control given the overlap in lifetimes when DAOTA-M2 is bound to G4 structures and non-G4 RNA [Fig. 1c].

Fixing with $4 \%$ PFA results in a drop in average $\tau_{\mathrm{w}}$ by ca. $1 \mathrm{~ns}$ to $10.6 \pm 1.1 \mathrm{~ns}$, an interesting result as it implies changes in the number of G4s present upon fixation [Fig. 3d]. Reassuringly, addition of PDS $(10 \mu \mathrm{M}, 1 \mathrm{hr})$ has the same response as in live cells, with $\tau_{\mathrm{w}}$ dropping to mean $=9.1 \pm 1.4 \mathrm{~ns}$ and median $=8.5$ $\pm 1.4 \mathrm{~ns}$. In this experiment, the bi-modal distribution (formed due to limited PDS uptake by some cells) is best represented using the median. Treatment of fixed cells with RNAse (RNA digestion monitored using RNASelect ${ }^{\mathrm{TM}}$, Supplementary Fig. 9) has no effect $\left(p=4.4 \times 10^{-1}\right)$ on the average $\tau_{\mathrm{w}}$, confirming that RNA in the cell nucleus does not affect DAOTA-M2 lifetime. DNAse treatment, however, did result in a drop in nuclear lifetime to $9.3 \pm 0.9 \mathrm{~ns}$. This value falls in-between that of DAOTA-M2 bound to dsDNA (median $=8.5 \pm 1.4 \mathrm{~ns}$ ) and in a mixture of $\mathrm{dsDNA} / \mathrm{G} 4$ (10.6 $\pm 1.1 \mathrm{~ns}$ in fixed cells). This pattern is replicated in the Xenopus egg extract experiment described above [Fig. 1d].

Thus, our fixed cell experiments confirm that nuclear RNA does not contribute to the high DAOTA-M2 lifetime observed in fixed cells; this data gives us confidence that RNA is unlikely to interfere with live cell experiments. Therefore, the DAOTA-M2 lifetime can be attributed to G4 DNA structure formation. At the same time our data seem to indicate that more G4s are stained by DAOTA-M2 in live rather than in fixed cells (all of which are being equally displaced by PDS), although the effect of fixation on other cellular components and its knock-on effect on DAOTAM2 binding cannot be excluded.

Use of DAOTA-M2 to investigate helicases in live cells. We next investigated if DAOTA-M2 could report on the dynamics of G4 DNA inside live cells. We chose to disrupt the expression of 
(a)

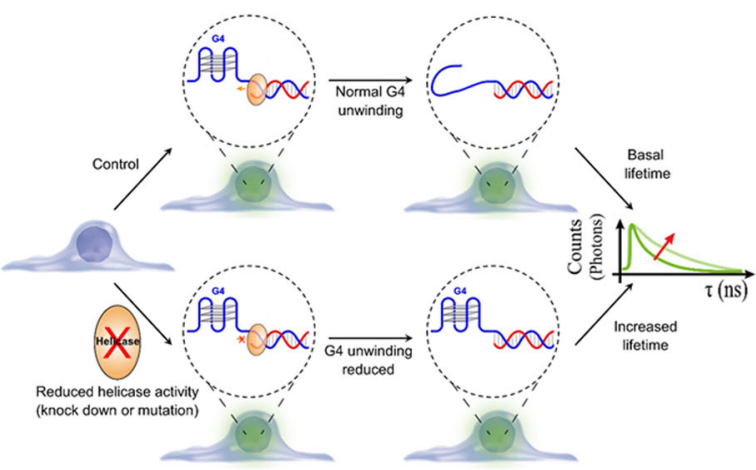

(b)

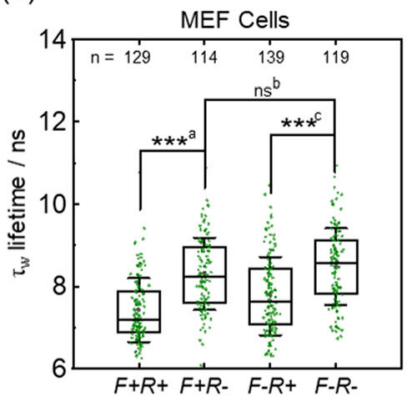

(c)

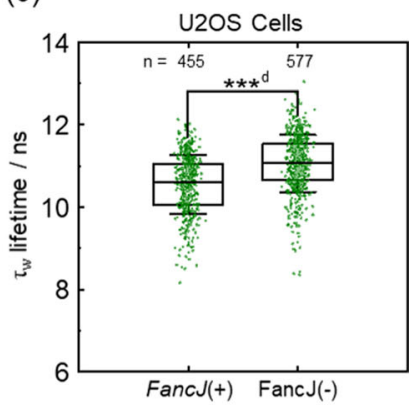

(d)
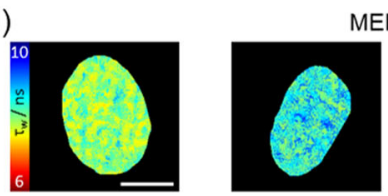

MEF Cells
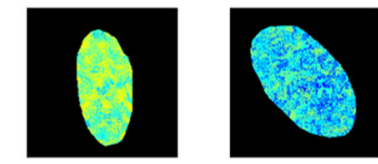

$F+R+$

$F+R-$

F-R+

$F-R-$

Fig. 4 FLIM analysis of FancJ and RTEL1 expression in mutant MEF and U2OS cells using DAOTA-M2. $F+R+=$ Fanc $J(+) / R T E L 1(+), F+R-=$ Fanc $J(+) / R T E L 1(-), F-R+=$ Fanc $J(-) / R T E L 1(+)$, and $F-R-=$ Fanc $J$ $(-) / R T E L 1(-)$. a Schematic showing how reduced FancJ or RTEL1 helicase expression results in longer DAOTA-M2 lifetimes $\left(\tau_{\mathrm{w}}\right)$. b Box plot of mean nuclear lifetimes $\left(\tau_{\mathrm{w}}\right)$ for $F+R+, F+R-, F-R+$ and $F-R-$ MEF cells. Cells were incubated with a null adenovirus $(R+)$, or incubated with CRE adenovirus $(R-)$ to delete RTEL1. Results from $\mathrm{n}$ cells as stated next to each box, over two independent experiments. c Box plot of mean nuclear lifetimes $\left(\tau_{w}\right)$ for U2OS cells transfected with silucif $[$ FancJ $(+)]$, or FancJ siRNA $[$ Fanc $J(-)]$ to knock-down FancJ. Results from $n$ cells as stated next to each box, over two independent experiments. d FLIM maps of cells from b displayed between 6 (red) and 10 (blue) ns and recorded at $512 \times 512$ resolution, representative of the cells from two independent experiments shown in b. Scale bars: $10 \mu \mathrm{m}$. Significance: ns $p>0.05,{ }^{\star} p<0.05,{ }^{\star \star} p<0.01$, ${ }^{\star \star \star *} p<0.001 .{ }^{a} p=1.1 \times 10^{-14}, t=-8.3, D F=228 .{ }^{b} p=1.4 \times 10^{-1}, t=-1.5$, $\mathrm{DF}=231 .{ }^{c} p=4.5 \times 10^{-9}, t=-6.1, \mathrm{DF}=252 .{ }^{d} p=2.7 \times 10^{-26}, t=-11.6$, $D F=959$. Source Data are available as a Source Data file for Fig. 4b, c.

the DNA helicases FancJ and RTEL1 [Fig. 4], which have been extensively reported, in vitro, to play a role in the resolution of G4s ${ }^{49-51}$, and monitor this using DAOTA-M2 in human and mouse cell lines. Cells lacking these proteins display general DNA replication stress, proposed to be the consequence of persisting $\mathrm{G} 4 \mathrm{~s}^{52,53}$. RTEL1 loss has been shown to cause sensitisation of mouse embryonic fibroblast (MEF) cells to G4 stabilising ligands, whilst FancJ loss did not - suggesting an increase in stable G4DNA with the loss of RTEL1, but little or no increase with the loss of Fanc $5^{54}$.

To alter the general G4 content in cellulo, we used mutant MEF cells in which expression of the FancJ gene is eliminated, and the RTEL1 gene can be deleted using an adenovirus ${ }^{54}$. This allows for four combinations of MEF cells with FancJ and/or RTEL1 deletion to be studied: FancJ $(+) / R T E L 1(+)$, FancJ $(+) / R T E L 1(-)$, FancJ $(-) / R T E L 1(+)$, and FancJ $(-) / R T E L 1(-)$.

Fanc $(+) / R T E L 1(+)$ cells treated with DAOTA-M2 showed average nuclear lifetime of $7.7 \pm 0.9 \mathrm{~ns}$ [Fig. S10c]. Lifetimes recorded in FancJ mutant MEF cells $[$ FancJ $(-) / R T E L 1(+)]$ showed a modest, but significant $\left(p=6.6 \times 10^{-3}\right)$ increase in the mean lifetime [ $8.0 \pm 1.0 \mathrm{~ns}$, Supplementary Fig. 10c].

As studying RTEL1 requires cells to be infected, we studied both uninfected MEF cells and MEF cells infected with a null adenovirus. Given we saw the potential for small variations in DAOTA-M2 lifetime after infection [Supplementary Fig. 10c], the null infected samples were used as our basis for comparison for RTEL1 mutants [Fig. 4b]. Under these conditions, FancJ $(+) / R T E L 1(+)$ cells treated with DAOTA-M2 showed average nuclear lifetimes of $7.4 \pm 0.8 \mathrm{~ns}$ [Fig. 4b]. A substantial effect $\left(p=1.1 \times 10^{-14}\right)$ was observed for the deletion of RTEL1 [FancJ $(+) / R T E L 1(-), 8.3 \pm 0.9$ ns, Fig. 4b]. A similarly significant effect $\left(p=4.5 \times 10^{-9}\right)$ was also seen for the deletion of RTEL1 in FancJ mutant cells, where the lifetime increased from $7.8 \pm 1.0 \mathrm{~ns}[$ FancJ $(-) / R T E L 1(+)$, Fig. $4 \mathrm{~b}]$ to $8.5 \pm 0.9 \mathrm{~ns}$ [Fanc] $(-) / R T E L 1(-)$, Fig. $4 \mathrm{~b}]$. There was no significant $\left(p=1.4 \times 10^{-1}\right)$ difference when comparing the single RTEL1 deletion [Fanc] $(+) / R T E L 1(-)$ ] to cells lacking both RTEL1 and FancJ [Fanc] $(-) / R T E L 1(-), 8.5 \pm 0.9$ ns, Fig. 4b]. In the absence of FancJ and/or $R T E L 1$, the longer DAOTA-M2 lifetimes suggest an increase in the stability and/or number of G4s. This is probably a direct effect and not a result of chromatin re-organisation since FancJ $(+) / R T E L 1(+)$ and $\operatorname{FancJ}(-) / R T E L 1(+)$ show similar chromatin staining by DAOTA-M2 and DAPI [Supplementary Fig. 5c-e], which do not correlate with the observed DAOTA-M2 lifetime [Supplementary Fig. 5h].

FancJ and RTEL1 deficient MEF cells are known to present a DNA damage response ${ }^{54}$, therefore to control for DDR influence on DAOTA-M2 lifetime, MEF cells were exposed to 2 Gy gamma irradiation. $\mathrm{\gamma H} 2 \mathrm{AX}$ positive MEF cells did not show DAOTA-M2 lifetime variation compared to non-irradiated MEFs [Supplementary Fig. 8c]. Additionally, we noticed that DAOTA-M2 treatment on all four $\mathrm{MEF}$ cell lines induced an equivalent increase in $\mathrm{\gamma H} 2 \mathrm{AX}$ intensity [Supplementary Fig. 4d, e] and a moderate accumulation of cells in S and G2 phases of the cell cycle [Supplementary Fig. 3c, d], when compared to control MEFs treated with DMSO. Importantly, these phenotypes in the mutant MEF cell lines are similar to the one observed in WT MEFs and so are independent of the genotypes. Therefore, the recorded fluctuations in DAOTA-M2 lifetimes between mutant and WT MEF cells are indicative of an effect of the absence of the helicases FancJ and RTEL1 on G4 homoeostasis, and not on DNA damage or cell cycle.

To corroborate this finding, the human homologue of FancJ was studied in U2OS cells transfected with well-established FancJ siRNA ${ }^{50,55-58}$ to achieve knock-down [98.6\% efficient from the WB, Figure S10a], alongside control cells transfected with siRNA against luciferase [Fig. 4c]. Cells where FancJ expression was knocked-down showed significantly $\left(p=2.7 \times 10^{-26}\right)$ longer lifetimes [11.1 $\pm 0.7 \mathrm{~ns}]$, compared to control cells [10.5 $\pm 0.7 \mathrm{~ns}]$.

These results demonstrate the potential for DAOTA-M2 to be used directly to monitor the role of G4 DNA in live cells without affecting cells through fixation or co-incubation.

In cellulo Fluorescence Lifetime Displacement Assay. G4s are considered as potential drug targets, and therefore it would be extremely useful to assess the ability of any given G4-targeted pharmaceutical to bind to this structure. Currently, a gold standard is to assess G4 DNA binders in vitro, with crucial information on whether they also target G4s in live cells missing. To add to our previous work using PDS as known G4 binder ${ }^{32}$, our 

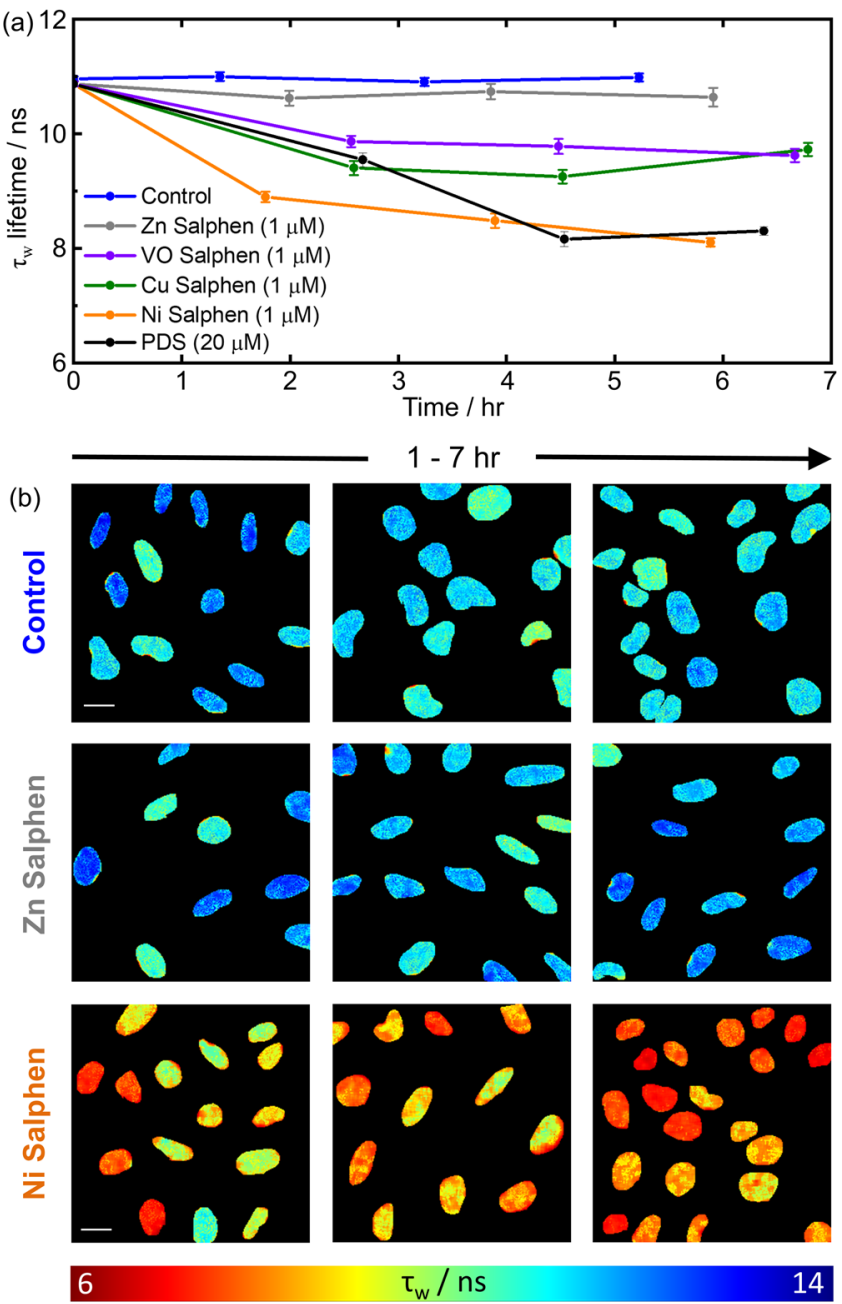

Fig. 5 FLIDA with the addition of different $\mathbf{G 4}$ binding compounds. a Mean nuclear DAOTA-M2 lifetime $\left(\tau_{\mathrm{w}}\right)$ of U2OS cells during incubation with G4 binders, error bars are \pm standard error of mean. Sample size is $\mathrm{n}$ cells over two independent experiments. For the time zero data point, $n=$ 623. For control (blue), $n=196,219,208$. For Zn Salphen (grey), $n=60$, 61,59 . For VO Salphen (purple), $n=71,67,63$. For Cu Salphen (green), $n=71,81,61$. For Ni Salphen (orange), $n=63,63,78$. For PDS (black), $n=$ $61,20,56$. In all conditions values for $\mathrm{n}$ are stated from earliest time point to latest. b Representative FLIM maps (displayed between 6 (red) and 14 (blue) ns) of the DAOTA-M2 emission (recorded at $256 \times 256$ resolution to speed-up data acquisition without affecting the average lifetime of each nucleus), following co-incubation with DMSO (Control), Zn-salphen, Nisalphen, and PDS. Images are representative of cells in the experiments shown in a. See Supplementary Fig. 12 for representative image during VOsalphen, $\mathrm{Cu}$-salphen and PDS incubation. Scale bar: $20 \mu \mathrm{m}$. Source Data are available as a Source Data file for Fig. 5a.

next aim was to develop a FLIM based Fluorescence Lifetime Indicator Displacement Assay (FLIDA) to investigate a range of G4 binders on their ability to displace DAOTA-M2 from live cells. As our test dataset, we chose the $\mathrm{Cu} / \mathrm{Ni} / \mathrm{VO} / \mathrm{Zn}$-salphen complexes described in the in vitro studies (see above) since they are structurally related but have different G4 affinities [Fig. 1g]. All cell cultures incubated with potential G4 binders showed good viability alone (at $1 \mu \mathrm{M} \mathrm{G} 4$ binder over $24 \mathrm{hr}$ ) and in combination with DAOTA-M2 at the experimental conditions used for imaging [Supplementary Fig. 11].

In cellulo FLIDA using Ni-salphen resulted in a rapid drop in lifetime over $2 \mathrm{hr}$ to $8.9 \pm 0.7 \mathrm{~ns}$, and after $6 \mathrm{hr}$ the lifetime had reached $8.1 \pm 0.6 \mathrm{~ns}$ [Fig. 5a, orange trace], consistent with PDS [Fig. 5a, black trace]. For Zn-salphen - which has been previously shown not to interact with G4s in vitro ${ }^{45}$ - no DAOTA-M2 displacement in live cells could be detected as the lifetime remains constant [Fig. 5a, grey trace]. Both $\mathrm{Cu}$ and VO-salphen complexes display intermediate behaviour with lifetimes that plateau at ca. $10 \mathrm{~ns}$ after $2 \mathrm{hr}$ [Fig. 5a and Supplementary Fig. 12]. For Ni, VO and Zn-salphens, the in vitro trend [Fig. 1g] is replicated in cellulo [Fig. 5], correlating with the binding affinity of each complex for $\mathrm{G} 4^{43-45}$. Cu-salphen, a strong $\mathrm{G} 4$ binder, did not show the magnitude of lifetime change expected from in vitro data, a possible consequence of lower cellular or nuclear uptake. Thus, it appears that dynamic measurements enabled by FLIDA in live cells offer significant advantages in monitoring the ability of potential G4 binders to target G4 structures.

\section{Discussion}

It is becoming increasingly evident that G4 DNA structures form in vivo and play important biological roles. However, to date it has been difficult to visualise these structures in real-time and in live cells. Based on our studies herein using FLIM with the optical probe DAOTA-M2, we have been able to establish a robust displacement assay (FLIDA) to quantitatively study the interaction of any molecule with G4 DNA in vitro and in live cells. The advantage of our displacement assay as compared to others previously reported, is that it is based on fluorescence lifetime rather than fluorescence intensity, which means the analysis is not dependent on concentrations and hence can be easily applied to a cellular environment. To achieve this, it was necessary to first confirm that other biomolecules present in cells would not interfere with the ability of DAOTA-M2 to differentiate different DNA topologies. The fluorescence lifetime of our probe in nucleic acid-depleted egg extracts supplemented with G4 or dsDNA are consistent with those in aqueous buffer. Additionally, we have shown that RNA does not contribute to the DAOTA-M2 lifetime, through the digestion of RNA in fixed cells. This was of importance given the overlap in in vitro lifetimes when DAOTA-M2 binds to non-G4 RNA, and G4 structures. In live cells, the average nuclear lifetime is ca. $11.0 \mathrm{~ns}$, which drops to ca. $8.5 \mathrm{~ns}$ on displacement using PDS (10 $\mu \mathrm{M}, 24 \mathrm{~h})$, a highly specific G4 binder. Given our extensive characterisation in buffered aqueous solutions, in extract and in fixed cells, this apparent drop in nuclear lifetime was assigned to the displacement of DAOTA-M2 from G4. In general, the lifetime values in cellulo are slightly higher than those from buffered and extract solutions. We attribute this difference to the change in physical and experimental conditions between bulk measurements in vitro and FLIM decays in cellulo (see experimental section). What is more important than the absolute lifetime value (which can be affected by physical parameters such as refractive index ${ }^{59,60}$ ), is the relative lifetime change between a control set of cells and those where the G4 structures have been disrupted.

To establish the validity of the cellular FLIDA assays, we carried out experiments with a series of structurally related G4 binders (i.e. the metal-salphens, with $\mathrm{M}=\mathrm{Cu}, \mathrm{Ni}, \mathrm{VO}, \mathrm{Zn}$ ). As indicated above, there is a clear structure-activity relationship between the in vitro binding affinities and the live cell FLIDA experiments. As a further negative control, we carried out FLIDA in live cells with DAPI, which localised in the nucleus (and bound to DNA) but did not change the nuclear $\tau_{\mathrm{w}}$ of DAOTA-M2, consistent with DAPI not displacing the probe from G4 DNA.

Interestingly, cell fixation using PFA decreased the DAOTAM2 lifetime which implies a difference in the nuclear distribution of G4 structures upon fixation (with a reduction in number of G4 sites available for binding with DAOTA-M2), a result that has 
not been observed previously. The FLIDA could be repeated in fixed cells using PDS, with displacement occurring to the same lifetime value as in live cells.

Having established how DAOTA-M2 interacts with G4 DNA using known G4 binders, we next designed experiments in which the nuclear G4 dynamics could be disturbed, without the need for co-incubation with strong G4 ligands. To achieve this, we reduced helicase enzyme expression in live cells through known protocols that knock-down FancJ in U2OS and knock-out FancJ and/or RTEL1, in MEF cells, respectively. Reducing the expression of known G4 helicases increases the number and/or stability of G4s, as the DAOTA-M2 lifetime increases. Studies using FancJ deficient human cells (U2OS and Hela) have reported that exposure to G4 ligands elicits a response in phenotypic markers (e.g. proliferation) when compared to wild type cells ${ }^{50}$, however, no such sensitivity was observed in FancJ deficient MEF cells ${ }^{54}$. We observe a modest lifetime increases when FancJ expression is reduced ( 0.5 and $0.3 \mathrm{~ns}$, for U2OS and MEF cells, respectively). This increase is smaller than the decrease in lifetime after PDS displacement (ca. $2.5 \mathrm{~ns}$ ), which is expected given that this helicase transiently targets specific regions of the genome and probably acts only on a proportion of the cellular G4 content inside each cell. Although the lifetime increase in MEF cells on loss of FancJ is small $(0.3 \mathrm{~ns})$, a larger effect is observed in MEF cells where RTEL1 has been deleted ( $0.6 \mathrm{~ns})$. This is consistent with studies showing that RTEL1 loss led to sensitisation by G4stabilising ligands, which was not observed with FANCJ loss. Taken together, these findings are in line with the suggestion that RTEL1 targets and resolves more efficiently genomic G4-forming sites than Fanc $^{54}$.

We also noticed that MEF cells have a lower baseline average nuclear lifetime compared to U2OS (ca. $8 \mathrm{~ns}$ and ca. $11 \mathrm{~ns}$, respectively). Embryonic MEF cells contain different euchromatin and heterochromatin organisation compared to U2OS cells ${ }^{61,62}$. While it is possible that the differences in chromosome packing between different cell lines have a direct effect on the lifetime of DAOTA-M2, we confirmed that high-intensity signal (indicating staining of chromatin) by DAOTA-M2 in the nucleus of both U2OS and MEF cells does not correlate with DAOTA-M2 lifetime (Supplementary Fig. 5). Additionally, as the PDS G4 displacement works in both live and fixed cells (Fig. 3), this lifetime change is unlikely to be only due to chromatin rearrangement.

Altering DNA helicase expression has multiple cellular and molecular effects on the genome, including transcriptome and RNA trafficking $51,63,64$, the possibility of forming ssDNA, doublestrand breaks and affecting RNA molecules. Treatment of U2OS cells with cisplatin showed a slight increase in nuclear lifetime, indicating that intra-strand DNA adducts and inter-strand crosslinks can result in a shift in DAOTA-M2 lifetime (Supplementary Fig. 8a). However, dsDNA breaks induced by $2 \mathrm{~Gy}$ gamma irradiation had no effect on the DAOTA-M2 lifetime (Figures S8b, c). In all MEF cells used in this study, incubation with DAOTA-M2 resulted in the same DDR response as measured using $\mathrm{\gamma H} 2 \mathrm{AX}$ foci (Supplementary Fig. 4d, e). Given this result, it is very unlikely that the significant increase in lifetime measurements observed in the helicase mutant experiments reflects an increase in binding of DAOTA-M2 to other DNA structures that might form in these genetic backgrounds. With these factors relating to chromosomal packing and DNA damage accounted for, we can say with confidence that FLIM analysis of DAOTA-M2 reports directly on the prevalence of G4 structures in live mammalian cells.

G4 DNA targeting is emerging as a novel design strategy in the development of therapeutic drugs for diseases such as cancer ${ }^{65}$, thus, a robust method to test their G4 binding in live cells is highly desirable. We have demonstrated that DAOTA-M2 can be used to investigate G4 dynamics and their interaction with G4 binders in cellulo in real time. This approach holds promise for monitoring the sensitivity of newly developed G4 targeting drugs (e.g., testing against various cancer cell lines, including patientderived samples) as well as for further understanding of the in vivo role of G4 DNA.

In summary, we have used DAOTA-M2 in combination with FLIM to monitor the formation of G4 DNA in the nuclei of live and fixed cells. We have developed a cellular assay to study the interaction of small molecules with G4 DNA, which can be applied to a wide range of drugs, which do not have intrinsic fluorescence. Our finding that cell fixation has a significant effect on the DAOTA-M2 lifetime, which must reflect a change in DNA topology, has wider implications for G4 studies that require fixations protocols. Additionally, our method can be used to study G4 DNA dynamics in live cells, for example when the expression of helicases known to unwind G4 in vitro is reduced or abolished. The knock-down of FancJ in U2OS or loss of FancJ and/or RTEL1 in MEF cells increase the nuclear lifetime, consistent with a reduction in amount of these enzymes. These experiments pave the way to directly study G4-related biological phenomena in live cells and to correlate the biological role of small molecules with their ability to target G4 DNA structures in live cells.

\section{Methods}

DAOTA-M2 and metal-salphen ( $\mathrm{Ni}, \mathrm{Cu}, \mathrm{VO}, \mathrm{Zn})$ complexes were synthesised as previously reported $32,44,45$. PDS was kindly donated by Dr. Marco Di Antonio, synthesised according to literature methods ${ }^{66,67}$. DAPI and cisplatin were purchased from commercial sources. Oligonucleotides $(c-M y c$ and ds26; sequences $=$ $5^{\prime}$-TGAGGGTGGGTAGGGTGGGTAA- ${ }^{\prime}$ and $5^{\prime}$-CAATCGGATCGAATTCGATCCGATTG- $3^{\prime}$, respectively) were purchased from Eurogentec, and dissolved in $10 \mathrm{mM}$ lithium cacodylate buffer at $\mathrm{pH} 7.3$. $\mathrm{KCl}$ was added to a final concentration of $100 \mathrm{mM}$, then the oligonucleotides were annealed at $95^{\circ} \mathrm{C}$ for $5-10$ min. Calf thymus DNA (CT-DNA, Sigma) was dissolved in the same cacodylate buffer, and $\mathrm{KCl}$ added to a final concentration of $100 \mathrm{mM}$. All oligonucleotide concentrations were determined unannealed using the molar extinction coefficients $13200 \mathrm{M}^{-1} \mathrm{~cm}^{-1}$ (base pair for CT-DNA), $228700 \mathrm{M}^{-1} \mathrm{~cm}^{-1}$ (strand for $c-M y c$ ), and $253200 \mathrm{M}^{-1} \mathrm{~cm}^{-1}$ (strand for ds26). Concentrations of G4 and dsDNA are expressed as per strand, and per base pair, respectively.

In vitro time-correlated single photon counting (TCSPC). Time-resolved fluorescence decays were obtained using an IBH $5000 \mathrm{~F}$ time-correlated singlephoton counting (TCSPC) device (Jobin Ybon, Horiba) equipped with a $467 \mathrm{~nm}$ NanoLED as an excitation source (pulse width $<200$ ps, HORIBA) with a $100 \mathrm{~ns}$ time window and 4096 time bins. Decays were detected at $\lambda_{\mathrm{em}}=575 \mathrm{~nm}( \pm 12 \mathrm{~nm})$ after passing through a $530 \mathrm{~nm}$ long-pass filter to remove any scattered excitation pulse. For experiments using Ni-, Cu- or VO-salphens, a $404 \mathrm{~nm}$ NanoLED excitation source was used. For experiments involving $\leq 0.2 \mu \mathrm{M}$ DAOTA-M2, 256 time bins were used detected at $\lambda_{\mathrm{em}}=575 \mathrm{~nm}( \pm 16 \mathrm{~nm})$ to increase signal intensity per bin. Decays were accumulated to 10000 counts at the peak of fluorescence decay. A neutral density filter was used for the instrument response function (IRF) measurements using a Ludox solution, detecting the emission at the excitation wavelength. Data collection was performed using DataStation v2.2 (HORIBA Scientific) and analysed using DAS6 v6.8 (HORIBA Scientific). Traces were fitted by iterative reconvolution to the equation $I(t)=I_{0}\left(\alpha_{1} \mathrm{e}^{-t / \tau 1}+\alpha_{2} \mathrm{e}^{-t / \tau 2}\right)$ where $\alpha_{1}$ and $\alpha_{2}$ are variables normalised to unity. The intensity-weighted average lifetime $\left(\tau_{\mathrm{w}}\right)$ was calculated using the equation: ${ }^{68}$

$$
\tau_{w}=\frac{\tau_{1}^{2} \alpha_{1}+\tau_{2}^{2} \alpha_{2}}{\tau_{1} \alpha_{1}+\tau_{2} \alpha_{2}}
$$

A prompt shift was included in the fitting to take into account differences in the emission wavelength between the IRF and measured decay. The goodness of fit was judged by consideration of the deviations from the model via a weighted residuals plot.

In vitro fluorescence lifetime displacement assay. DAOTA-M2 $(2 \mu \mathrm{M})$ was dissolved in $10 \mathrm{mM}$ lithium cacodylate buffer ( $\mathrm{pH}$ 7.3) supplemented with $100 \mathrm{mM}$ $\mathrm{KCl}$ and the time-resolved fluorescence decay was recorded. If needed, dsDNA (CT-DNA, $20 \mu \mathrm{M}$ ) was mixed with DAOTA-M2 and the decay recorded. Prefolded G4 DNA $(c-M y c, 4 \mu \mathrm{M})$ was then added and the decay recorded. Increasing amounts of the corresponding molecules under study were added and the fluorescence decay recorded until no further changes were observed. 


\section{In vitro fluorescence lifetime measurements with nucleic acid-depleted egg} extracts. Decay data for nucleic acid-depleted cell extract studies was acquired by mixing $33 \mu \mathrm{L}$ of nucleic acid-depleted Xenopus Laevis egg extracts ${ }^{38}$, with $12 \mu \mathrm{L}$ of $10 \mathrm{mM}$ lithium cacodylate buffer ( $\mathrm{pH} 7.3$ ) containing $100 \mathrm{mM} \mathrm{KCl}$, DAOTA-M2 (final concentration $2 \mu \mathrm{M}$ ) and oligonucleotide (final concentration: $c-M y c=4 \mu \mathrm{M}$ or ds26 $=44 \mu \mathrm{M}$ ). For samples where cell extract was not used, the same volume of $10 \mathrm{mM}$ lithium cacodylate buffer ( $\mathrm{pH} 7.3$ ) containing $100 \mathrm{mM} \mathrm{KCl}$ was used in its place. Lifetimes decays were recorded using a home-built TCSPC method described previously ${ }^{69}$ with data collected using SPCM v9.83 (Becker \& Hickl GmbH) Samples were excited using a pulsed diode laser (Becker \& Hickl GmbH, $477 \mathrm{~nm}$, $20 \mathrm{MHz})$ and emission collected at $575 \mathrm{~nm}( \pm 15 \mathrm{~nm})$, using a $550 \mathrm{~nm}$ long-pass filter to remove scattered excitation photons. Decay traces were fitted using the FLIMfit software tool developed at Imperial College London $^{70}$ (v5.1.1, Sean Warren, Imperial College London) to a bi-exponential function, and the mean weighted lifetime $\left(\tau_{\mathrm{w}}\right)$ calculated using Eq. (1).

General cell culture. Human Bone Osteosarcoma Epithelial Cells (U2OS, from ATCC) were grown in high glucose Dulbecco's modified Eagle medium (DMEM) containing $10 \%$ fetal bovine serum at $37^{\circ} \mathrm{C}$ with $5 \% \mathrm{CO}_{2}$ in humidified air.

In cellulo fluorescence lifetime displacement assay. Cells were seeded on chambered coverglass $\left(1.5 \times 10^{4}\right.$ cells, $\left.250 \mu \mathrm{l}, 0.8 \mathrm{~cm}^{2}\right)$ for $24 \mathrm{~h}$, before washing with phosphate-buffered saline (PBS) and adding fresh media containing DAOTA-M2 $(20 \mu \mathrm{M}, 250 \mu \mathrm{l})$ for a further $24 \mathrm{~h}$. For $24 \mathrm{hr}$ co-incubation experiments, the compound under study was added with DAOTA-M2 and imaged $24 \mathrm{hr}$ later. For $<$ $24 \mathrm{hr}$ co-incubation experiments, the compound udder study was added directly to the incubation media after $24 \mathrm{hr}$ DAOTA-M2 incubation, and images were taken over time. Cells were imaged directly in the final incubation media. For time dependant measurements (Fig. 5), $t=0$ cannot be measured directly as cells require equilibrating before imaging. Therefore, $t=0$ was calculated from an average of all the control time points.

Fixed Cell experiments. Cells were seeded on chambered coverglass $\left(1.5 \times 10^{4}\right.$ cells, $\left.250 \mu \mathrm{l}, 0.8 \mathrm{~cm}^{2}\right)$ for $24 \mathrm{~h}$, before washing with PBS and adding fresh media containing DAOTA-M2 $(20 \mu \mathrm{M}, 250 \mu \mathrm{l})$ for a further $24 \mathrm{~h}$. Cells were washed $(\mathrm{x} 3)$ in ice-cold PBS before incubation in ice-cold paraformaldehyde (PFA, 4\% in PBS) solution for $10 \mathrm{~min}$, and a further wash (x3) with ice-cold PBS. Fixed cells were further treated with PDS $\left(10 \mu \mathrm{M}, 1 \mathrm{~h}, 21^{\circ} \mathrm{C}\right)$, RNAse $\mathrm{A}\left(1 \mathrm{mg} \mathrm{ml}^{-1}, 10 \mathrm{~min}, 21^{\circ} \mathrm{C}\right.$, Merck) or DNAse (200 Units well ${ }^{-1}, 1 \mathrm{hr}, 37^{\circ} \mathrm{C}$, Qiagen). DAPI was stained at $0.5 \mu \mathrm{M}(5 \mathrm{~min})$ and RNASecelct ${ }^{\mathrm{TM}}$ at $0.5 \mu \mathrm{M}(20 \mathrm{~min})$ in PBS. To minimise the impact of fixation on the DAOTA-M2 lifetime due to the refractive index of the media ${ }^{59}$, all FLIM experiments on fixed cells were performed without fixative, under a solution of PBS.

Cell culture for helicase knock-down and knock-out experiments. For FancJ helicase knock-down treatment, a solution of $30 \mathrm{nM}$ siRNA (SigmaAldrich, $5^{\prime}$ GUACAGUACCCCACCUUAU $-3^{\prime}$ ) and DharmaFECT reagent (used as per manufacturer's instructions, Dharmacon) in serum-free DMEM was prepared and incubated at RT for $30 \mathrm{~min}$. $400 \mu \mathrm{L}$ of this solution was mixed with $2.1 \mathrm{~mL}$ DMEM containing $10 \%$ FBS and used to seed cells $\left(1.6 \times 10^{5}\right.$ cells, $\left.2.50 \mathrm{ml}, 9.6 \mathrm{~cm}^{2}\right)$ for 16 $\mathrm{hr}$ at $37^{\circ} \mathrm{C}$. The growth medium was replenished, and cells further incubated for $24 \mathrm{~h}$ before reseeding on chambered coverglass $\left(5.0 \times 10^{4}\right.$ cells, $\left.400 \mu \mathrm{l}, 0.8 \mathrm{~cm}^{2}\right)$ with the addition of DAOTA-M2 $(10 \mu \mathrm{M})$ for a further $24 \mathrm{hr}$ before imaging. Cells treated analogously using an siRNA for Luciferase (Dharmacon, 5'- UCGAAGUAUUCCGCGUACG - $3^{\prime}$ ) were used as a control. The knockdown efficiency was assessed by Western blot for FancJ compared to actin [Figure S10a]

Mutant mouse embryonic fibroblast (MEF) cells were used in which the FancJ gene is compromised by a gene trap cassette, eliminating expression of the FancJ ORF, resulting in a null allele ${ }^{43}$. In these cells the RTEL1 gene is flanked by lox $P$ sites, allowing RTEL1 deletion by infection with adenovirus harbouring the CRE recombinase protein. RTEL1 ${ }^{F / F} \mathrm{Fanc}^{+/-}$and RTEL1 $^{\mathrm{F} / \mathrm{F}} \mathrm{Fanc}^{-1-}$ MEF cells (a kind gift from S. Boulton) were cultured as described above for U2OS cells. For studies of RTEL1 knock-out, cells were left without infection, or cells were incubated with $30 \mathrm{MOI}$ of either Null or CRE adenovirus (Vector biolabs) with 1x polybrene and 2\% FBS in serum-free DMEM for $2 \mathrm{hr}$ at $37^{\circ} \mathrm{C}$ with shaking, before returning to culture. This infection was repeated after $48 \mathrm{hr}$. Cells were grown for a further $72 \mathrm{hr}$ before preparation for FLIM.

For FLIM, cells were reseeded on chambered coverglass (1.5-5 $\times 10^{4}$ cells, 200 $\left.\mu \mathrm{l}, 0.8 \mathrm{~cm}^{2}\right)$ for $24-48 \mathrm{~h}$ in media, incubated with DAOTA-M2 $(20 \mu \mathrm{M})$ for $24 \mathrm{~h}$ before imaging.

MTS cytoxicity assay. U2OS cells were seeded $\left(5 \times 10^{3}\right.$ cells, $\left.100 \mu \mathrm{l}, 32.2 \mathrm{~mm}^{2}\right)$ in a 96-well plate. After $24 \mathrm{~h}$, compounds under study were added at the appropriate concentration in triplicate $(150 \mu \mathrm{l})$. After a further $24 \mathrm{~h}$, the MTS/PMS reagents were added according to the Promega MTS Assay protocol. The average absorbance of the triplicate wells was recorded at $492 \mathrm{~nm}$, and where applicable, readings were corrected for compound absorbance by subtracting the compound-only control run in parallel. Wells were maintained with DMSO (only cells) as 100\% and the maximum compound concentration as $0 \%$ viability. For experiments involving co-incubation with DAOTA-M2, cells with only DAOTA-M2 incubation were used as $100 \%$ and no cells as $0 \%$. Absolute $\mathrm{IC}_{50}$ was determined from the doseresponse curve of absorbance vs. logarithm of concentration of compound.

Fluorescence imaging. DAPI emission $(400-450 \mathrm{~nm})$ was collected following multiphoton excitation at $760 \mathrm{~nm}$ with 665 and $680 \mathrm{~nm}$ cut off filters. RNASelect ${ }^{\mathrm{TM}}$ emission (495-545 nm) was collected following $488 \mathrm{~nm}$ excitation. When RNASelect was present, DAOTA-M2 emission (570-700 nm) was collected following $561 \mathrm{~nm}$ excitation. Software for confocal imaging and analysis was LAS AF v.2.6.0 (Leica).

Fluorescence lifetime imaging microscopy (FLIM). FLIM was performed through time-correlated single-photon counting (TCSPC), using an inverted confocal laser scanning microscope (Leica, SP5 II) and a SPC-830 single-photon counting card (Becker \& Hickl GmbH). A pulsed diode laser (Becker \& Hickl $\mathrm{GmbH}, 477 \mathrm{~nm}, 20 \mathrm{MHz}$ ) was used as the excitation source, with a PMC-100-1 photomultiplier tube (Hamamatsu) detector. Software for collecting FLIM images was SPCM v9.83 (Becker \& Hickl GmbH). Fluorescence emission $(550-700 \mathrm{~nm})$ was collected through a $200 \mu \mathrm{m}$ pinhole for an acquisition time sufficient to obtain signal strength suitable for decay fitting, or a maximum of $1000 \mathrm{~s}$. For all live-cell imaging, cells were mounted (on chambered coverglass slides) in the microscope stage, heated by a thermostat (Lauda GmbH, E200) to $37( \pm 0.5)^{\circ} \mathrm{C}$, and kept under an atmosphere of $5 \% \mathrm{CO}_{2}$ in air. A $100 \mathrm{x}$ (oil, $\mathrm{NA}=1.4$ ) or $63 \mathrm{x}$ (water, $\mathrm{NA}=1.2$ ) objective was used to collect images at either $256 \times 256$ pixel resolution or at $512 \times$ 512 pixel resolution, as stated in the text. The IRF used for deconvolution was recorded using reflection of the excitation beam from a glass cover slide.

Lifetime data were fitted using the FLIMfit software tool developed at Imperial College London (v5.1.1, Sean Warren, Imperial College London) ${ }^{70}$ to a bi-exponential function, and the mean weighted lifetime $\left(\tau_{\mathrm{w}}\right)$ calculated using Eq. $(1) .7 \times 7$ and $9 \times$ 9 square binning was used to increase signal strength for images recorded at $256 \times 256$ and $512 \times 512$ resolution, respectively. A scatter parameter was added to the decay fitting to account for scattered excitation light. Before fitting, a mask was applied to the images to analyse individual cell nuclei. Fitted lifetime data for each pixel within a single cell nucleus were pooled to find average and median nuclear $\tau_{w}$ values. A threshold was applied to the average of each nucleus to require a minimum of 300 at the peak of the decay and a goodness-of-fit measured by $\chi^{2}$ of less than 2 . Average nuclear intensity in FLIM images was calculated from the peak maximum of the fitted decay (excluding scatter), averaged across the nucleus.

Gamma irradiation. Chamber slides containing either U2OS or MEF cells were inserted into the Irradiator (GSR D1 Cell Irradiator) for $50 \mathrm{~s}$ to irradiate cells to 2 Gy. Control cells were left outside for the equivalent time. Samples for FLIM were then imaged as above, except MEF cells which were imaged using a 20x $(\mathrm{NA}=0.7)$ objective. To confirm DNA damage, slides were further incubated for $30 \mathrm{~min}$ to allow initiation of damage repair by the cells, then imaged for $\mathrm{\gamma H} 2 \mathrm{AX}$ immunofluorescence staining.

XH2AX staining. Cells were permeabilised with Triton X-100 buffer (0.5\% Triton $\mathrm{X}-100 ; 20 \mathrm{mM}$ Tris pH $8 ; 50 \mathrm{mM} \mathrm{NaCl} ; 3 \mathrm{mM} \mathrm{MgCl}_{2} ; 300 \mathrm{mM}$ sucrose) at RT for 5 $\mathrm{min}$ and then fixed in $3 \%$ formaldehyde/2\% sucrose in PBS for $15 \mathrm{~min}$ at RT and washed with PBS (x3). After a 10 min permeabilisation step and a wash in PBS, nuclei were incubated with blocking solution (10\% goat serum in PBS) for $30 \mathrm{~min}$ at $37^{\circ} \mathrm{C}$ and stained with mouse-anti- $\gamma \mathrm{H} 2 \mathrm{AX}(1 / 500$, Millipore $05-636)$ for $1 \mathrm{~h}$ at $37^{\circ} \mathrm{C}$ followed by $\mathrm{O} / \mathrm{N}$ incubation at $4{ }^{\circ} \mathrm{C}$. After washing in PBS (x3), slides were incubated with secondary goat anti-mouse Alexa 488 antibody (1/400, Life Technologies A11001) for $40 \mathrm{~min}$ at $37^{\circ} \mathrm{C}$, washed in PBS (x3), and incubated with ethanol series $(70,80,90,100 \%)$. Slides were mounted with antifade reagent (ProLong Gold, Invitrogen) containing DAPI, and images were captured with Zeiss microscope using Carl Zeiss software.

Fluorescence-activated cell sorting (FACS). Cells in culture were treated with BrdU $(10 \mu \mathrm{M})$ in medium for $30 \mathrm{~min}$ before collection with trypsin and resuspended in PBS $(300 \mu \mathrm{L})$. Ice-cold methanol $(700 \mu \mathrm{L})$ was added dropwise with mixing and the samples were stored at $-20^{\circ} \mathrm{C}$ for a minimum of $2 \mathrm{~h}$. Fixed cells were harvested by centrifugation and incubated with pepsin $(2 \mathrm{~mL}, 0.2 \mathrm{mg} / \mathrm{mL}$ in $2 \mathrm{M} \mathrm{HCl}, \mathrm{RT}$ ) for $20 \mathrm{~min}$. Samples were washed with PBS and resuspended in $0.5 \mathrm{~m}$ : block solution (PBS, $0.5 \%$ Tween $20,0.5 \%$ BSA) with aBrdU-FITC conjugate $(20 \mu \mathrm{L})$ for $1 \mathrm{~h}$ at RT. Samples were washed with the same solution then resuspended in PBS containing RNaseA $\left(0.5 \mathrm{mg} / \mathrm{mL}, 1 \mathrm{~mL}, 37^{\circ} \mathrm{C}, 15 \mathrm{~min}\right)$. Propidium iodide $(10 \mu \mathrm{g} / \mathrm{mL})$ was added for $5 \mathrm{~min}$ at RT and samples were stored at $4{ }^{\circ} \mathrm{C}$ for FACS. Data and graphs were analysed and generated using FlowJo software (BD biosciences), using Watson (Pragmatic) module.

Western Blot. Protein was extracted from cells using a lysis buffer $(40 \mathrm{mM} \mathrm{NaCl}$, $25 \mathrm{mM}$ Tris pH 8, $2 \mathrm{mM} \mathrm{MgCl}, 0.05 \%$ SDS, 2x Complete EDTA-free protease inhibitor (Roche), $0.4 \mu \mathrm{L} \mathrm{mL}^{-1}$ benzonase) with protein concentration determined by Bradford assay, comparing to BSA standards to ensure loading of an equal mass of protein into each lane. Protein and Laemmli buffer were heated to $100^{\circ} \mathrm{C}$ for 5 min before loading into gel. For U2OS, NuPAGE Novex $4-12 \%$ Bis-Tris Gel (Invitrogen) was used. For MEFs, NuPAGE Novex 3-8\% Tris-Acetate Gel 
(Invitrogen) was used. Samples were run on gels for $2 \mathrm{hr}$ before transfer from gel to a nitrocellulose membrane. Antibodies used to bind proteins on membrane were pAb rabbit BRIP1/FANCJ antibody (1/10000, Novus Biologicals NBP1-31883), pAb rabbit RTEL1 antibody (1/5000, Novus Biologicals NBP2-22360). For loading control, mAb mouse anti- $\beta$-actin antibody (1/5000, Abcam ab8226) was used with U2OS and mAb mouse anti- $\alpha$-Tubulin (1/10000, Sigma Aldrich T6199) was used with MEFs. Secondary antibodies used were: pAb swine anti-rabbit immunoglobulins/HRP (1/10000, Dako P0217) and pAb goat anti-mouse immunoglobulins/ HRP (1/5000, invitrogen A16078). Visualisation was performed by exposure onto photographic film for U2OS and visualisation using Amersham ImageQuant 800 for MEFs. Full uncropped scans are available in the source data file.

Statistics. Results are expressed as mean \pm SD (unless stated otherwise). Twotailed non-paired $\mathrm{t}$-tests were performed using OriginPro v9.55. $p$-values, $t$-values, and degrees of freedom (DF) are stated in the figure captions. Significance: $\mathrm{ns} p>$ $0.05,{ }^{*} p<0.05,{ }^{* *} p<0.01,{ }^{* * *} p<0.001 . n$ values are the total cell nuclei that meet the threshold requirements. For box plots, the box represents $25-75 \%$ range, error bars are the mean $\pm \mathrm{SD}$, horizontal line is the median and the grey dot is the mean.

Reporting Summary. Further information on research design is available in the Nature Research Reporting Summary linked to this article.

\section{Data availability}

The data that support this study are present in the manuscript and supplementary information, and are available from the corresponding author upon request. Source Data are provided with this paper.

Received: 26 March 2020; Accepted: 27 November 2020; Published online: 08 January 2021

\section{References}

1. Bochman, M. L., Paeschke, K. \& Zakian, V. A. DNA secondary structures: stability and function of G-quadruplex structures. Nat. Rev. Genet. 13, 770-780 (2012).

2. Murat, P. \& Balasubramanian, S. Existence and consequences of G-quadruplex structures in DNA. Curr. Opin. Genet. Dev. 25, 22-29 (2014).

3. Rhodes, D. \& Lipps, H. J. G-quadruplexes and their regulatory roles in biology. Nucleic Acids Res. 43, 8627-8637 (2015).

4. Neidle, S. Quadruplex nucleic acids as targets for anticancer therapeutics. Nat. Rev. Chem. 1, 10 (2017).

5. Huppert, J. L. \& Balasubramanian, S. Prevalence of quadruplexes in the human genome. Nucleic Acids Res. 33, 2908-2916 (2005).

6. Todd, A. K., Johnston, M. \& Neidle, S. Highly prevalent putative quadruplex sequence motifs in human DNA. Nucleic Acids Res. 33, 2901-2907 (2005).

7. Bedrat, A., Lacroix, L. \& Mergny, J. L. Re-evaluation of G-quadruplex propensity with G4Hunter. Nucleic Acids Res. 44, 1746-1759 (2016).

8. Chambers, V. S. et al. High-throughput sequencing of DNA G-quadruplex structures in the human genome. Nat. Biotechnol. 33, 877-881 (2015).

9. Hänsel-Hertsch, R. et al. G-quadruplex structures mark human regulatory chromatin. Nat. Genet. 48, 1267-1272 (2016).

10. Hänsel-Hertsch, R., Spiegel, J., Marsico, G., Tannahill, D. \& Balasubramanian, S. Genome-wide mapping of endogenous G-quadruplex DNA structures by chromatin immunoprecipitation and high-throughput sequencing. Nat. Protoc. 13, 551-564 (2018).

11. Fouquerel, E., Parikh, D. \& Opresko, P. DNA damage processing at telomeres: the ends justify the means. DNA Repair 44, 159-168 (2016).

12. De Magis, A. et al. DNA damage and genome instability by G-quadruplex ligands are mediated by R loops in human cancer cells. Proc. Natl Acad. Sci. USA 116, 816-825 (2019).

13. Mendoza, O., Bourdoncle, A., Boule, J. B., Brosh, R. M. \& Mergny, J. L. Gquadruplexes and helicases. Nucleic Acids Res. 44, 1989-2006 (2016).

14. Brown, B. A. et al. Isolation and characterization of a monoclonal antiquadruplex DNA antibody from autoimmune "viable motheaten" mice. Biochemistry 37, 16325-16337 (1998).

15. Schaffitzel, C. et al. In vitro generated antibodies specific for telomeric guanine-quadruplex DNA react with Stylonychia lemnae macronuclei. Proc. Natl Acad. Sci. U. S. A. 98, 8572-8577 (2001).

16. Biff, G., Tannahill, D., McCafferty, J. \& Balasubramanian, S. Quantitative visualization of DNA G-quadruplex structures in human cells. Nat. Chem. 5, 182-186 (2013).

17. Biff, G., Di Antonio, M., Tannahill, D. \& Balasubramanian, S. Visualization and selective chemical targeting of RNA G-quadruplex structures in the cytoplasm of human cells. Nat. Chem. 6, 75-80 (2014).
18. Liu, H. Y. et al. Conformation selective antibody enables genome profiling and leads to discovery of parallel G-quadruplex in human telomeres. Cell Chem. Biol. 23, 1261-1270 (2016).

19. Henderson, A. et al. Detection of G-quadruplex DNA in mammalian cells. Nucleic Acids Res. 42, 860-869 (2014).

20. Douglas, M. P. \& Rogers, S. O. DNA damage caused by common cytological fixatives. Mutat. Res., Fundam. Mol. Mech. Mutagen. 401, 77-88 (1998).

21. Srinivasan, M., Sedmak, D. \& Jewell, S. Effect of fixatives and tissue processing on the content and integrity of nucleic acids. Am. J. Pathol. 161, 1961-1971 (2002)

22. Chilka, P., Desai, N. \& Datta, B. Small molecule fluorescent probes for Gquadruplex visualization as potential cancer theranostic agents. Molecules $\mathbf{2 4}$, 752 (2019).

23. Pandith, A., Siddappa, R. G. \& Seo, Y. J. Recent developments in novel blue/ green/red/NIR small fluorescent probes for in cellulo tracking of RNA/DNA G-quadruplexes. J. Photochem. Photobiol. C. 40, 81-116 (2019).

24. Monchaud D. In Annual Reports in Medicinal Chemistry. (ed. Neidle, S.) 54, 133-160 (2020).

25. Mohanty, J. et al. Thioflavin $\mathrm{T}$ as an efficient inducer and selective fluorescent sensor for the human telomeric G-quadruplex DNA. J. Am. Chem. Soc. 135, 367-376 (2013).

26. $\mathrm{Xu}, \mathrm{S}$. J. et al. Thioflavin $\mathrm{T}$ as an efficient fluorescence sensor for selective recognition of RNA G-quadruplexes. Sci. Rep. 6, 24793 (2016).

27. Guan, A. J. et al. Ethyl-substitutive Thioflavin T as a highly-specific fluorescence probe for detecting G-quadruplex structure. Sci. Rep. 8, 2666 (2018).

28. Xue, C., Lin, T. Y. W., Chang, D. \& Guo, Z. F. Thioflavin T as an amyloid dye fibril quantification, optimal concentration and effect on aggregation. $R$. Soc. OpenSci. 4, 160696 (2017).

29. Stsiapura, V. I. et al. Thioflavin $\mathrm{T}$ as a molecular rotor: fluorescent properties of Thioflavin $\mathrm{T}$ in solvents with different viscosity. J. Phys. Chem. B 112, 15893-15902 (2008)

30. Di Antonio, M. et al. Single-molecule visualization of DNA G-quadruplex formation in live cells. Nat. Chem. 12, 832-837 (2020).

31. Rajput, C., Rutkaite, R., Swanson, L., Haq, I. \& Thomas, J. A. Dinuclear monointercalating Ru-II complexes that display high affinity binding to duplex and quadruplex DNA. Chem.: Eur. J. 12, 4611-4619 (2006).

32. Shivalingam, A. et al. The interactions between a small molecule and Gquadruplexes are visualized by fluorescence lifetime imaging microscopy. Nat. Commun. 6, 8178 (2015).

33. Tseng, T. Y. et al. The G-quadruplex fluorescent probe 3,6-bis(1-methyl-2vinyl-pyridinium) carbazole diiodide as a biosensor for human cancers. Sci. Rep. 8, 16082 (2018).

34. Tseng, T. Y., Chu, I. T., Lin, S. J., Li, J. \& Chang, T. C. Binding of small molecules to G-quadruplex DNA in cells revealed by fluorescence lifetime imaging microscopy of o-BMVC foci. Molecules 24, 35 (2019).

35. Liu, L.-Y. et al. Content detection of G-Quadruplex DNA in live cells based on photon counts and complex structures. Angew. Chem. https://doi.org/10.1002/ ange.202002422 (2020).

36. Kotar, A. et al. NMR structure of a triangulenium-based long-lived fluorescence probe bound to a G-Quadruplex. Angew. Chem. -Int. Ed. 55, 12508-12511 (2016)

37. Shivalingam, A. et al. Trianguleniums as optical probes for G-quadruplexes: A photophysical, electrochemical, and computational study. Chem.: Eur. J. 22, 4129-4139 (2016).

38. Hoogenboom, W. S., Klein Douwel, D. \& Knipscheer, P. Xenopus egg extract a powerful tool to study genome maintenance mechanisms. Dev. Biol. 428 , 300-309 (2017).

39. Koirala, D. et al. A single-molecule platform for investigation of interactions between G-quadruplexes and small-molecule ligands. Nat. Chem. 3, 782-787 (2011)

40. Le, D. D., Di Antonio, M., Chan, L. K. M. \& Balasubramanian, S. Gquadruplex ligands exhibit differential G-tetrad selectivity. Chem. Commun. 51, 8048-8050 (2015).

41. Ray, S. et al. Custom DNA microarrays reveal diverse binding preferences of proteins and small molecules to thousands of G-quadruplexes. ACS Chem. Biol. 15, 925-935 (2020).

42. Tanious, F. A., Veal, J. M., Buczak, H., Ratmeyer, L. S. \& Wilson, W. D. DAPI (4',6-diamidino-2-phenylindole) binds differently to DNA and RNA - Minorgroove binding at AT sites and intercalation at AU sites. Biochemistry 31, 3103-3112 (1992)

43. Campbell, N. H. et al. Molecular basis of structure-activity relationships between salphen metal complexes and human telomeric DNA quadruplexes. J. Med. Chem. 55, 209-222 (2012).

44. Reed, J. E., Arnal, A. A., Neidle, S. \& Vilar, R. Stabilization of G-quadruplex DNA and inhibition of telomerase activity by square-planar nickel(II) complexes. J. Am. Chem. Soc. 128, 5992-5993 (2006).

45. Arola-Arnal, A., Benet-Buchholz, J., Neidle, S. \& Vilar, R. Effects of metal coordination geometry on stabilization of human telomeric quadruplex DNA 
by square-planar and square-pyramidal metal complexes. Inorg. Chem. $\mathbf{4 7}$, 11910-11919 (2008).

46. Abd Karim, N. H. et al. Salphen metal complexes as tunable G-quadruplex binders and optical probes. RSC Adv. 4, 3355-3363 (2014).

47. Rodriguez, R. et al. Small-molecule-induced DNA damage identifies alternative DNA structures in human genes. Nat. Chem. Biol. 8, 301-310 (2012).

48. Shen, D. W., Pouliot, L. M., Hall, M. D. \& Gottesman, M. M. Cisplatin resistance: a cellular self-defense mechanism resulting from multiple epigenetic and genetic changes. Pharmacol. Rev. 64, 706-721 (2012).

49. Leon-Ortiz, A. M., Svendsen, J. \& Boulton, S. J. Metabolism of DNA secondary structures at the eukaryotic replication fork. DNA Repair 19, 152-162 (2014).

50. Wu, Y. L., Shin-ya, K. \& Brosh, R. M. FANCJ helicase defective in Fanconia anemia and breast cancer unwinds G-quadruplex DNA to defend genomic stability. Mol. Cell. Biol. 28, 4116-4128 (2008).

51. Vannier, J. B. et al. RTEL1 Is a replisome-associated helicase that promotes telomere and genome-wide replication. Science 342, 239-242 (2013).

52. Sarkies, P. et al. FANCJ coordinates two pathways that maintain epigenetic stability at G-quadruplex DNA. Nucleic Acids Res. 40, 1485-1498 (2012)

53. Vannier, J. B., Pavicic-Kaltenbrunner, V., Petalcorin, M. I. R., Ding, H. \& Boulton, S. J. RTEL1 dismantles T loops and counteracts telomeric G4-DNA to maintain telomere integrity. Cell 149, 795-806 (2012).

54. Matsuzaki, K., Borel, V., Adelman, C. A., Schindler, D. \& Boulton, S. J. FANCJ suppresses microsatellite instability and lymphomagenesis independent of the Fanconi anemia pathway. Genes Dev. 29, 2532-2546 (2015).

55. Litman, R. et al. BACH1 is critical for homologous recombination and appears to be the Fanconi anemia gene product FANCJ. Cancer Cell 8, 255-265 (2005).

56. Greenberg, R. A. et al. Multifactorial contributions to an acute DNA damage response by BRCA1/BARD1-containing complexes. Genes Dev. 20, 34-46 (2006).

57. Zhang, F., Bick, G., Park, J. Y. \& Andreassen, P. R. MDC1 and RNF8 function in a pathway that directs BRCA1-dependent localization of PALB2 required for homologous recombination. J. Cell Sci. 125, 6049-6057 (2012).

58. Bharti, S. K. et al. Specialization among iron-sulfur cluster helicases to resolve G-quadruplex DNA structures that threaten genomic stability. J. Biol. Chem. 288, 28217-28229 (2013).

59. Joosen, L., Hink, M. A., Gadella, T. W. J. \& Goedhart, J. Effect of fixation procedures on the fluorescence lifetimes of Aequorea victoria derived fluorescent proteins. J. Microsc. 256, 166-176 (2014).

60. Ganguly, S., Clayton, A. H. A. \& Chattopadhyay, A. Fixation alters fluorescence lifetime and anisotropy of cells expressing EYFP-tagged serotonin (1A) receptor. Biochem. Biophys. Res. Commun. 405, 234-237 (2011).

61. Tajbakhsh, J., Gertych, A., Fagg, W. S., Hatada, S. \& Fair, J. H. Early in vitro differentiation of mouse definitive endoderm is not correlated with progressive maturation of nuclear DNA methylation patterns. PLOS ONE 6 (2011).

62. Sathyan, K. M., Shen, Z., Tripathi, V., Prasanth, K. V. \& Prasanth, S. G. A BEN-domain-containing protein associates with heterochromatin and represses transcription. J. Cell Sci. 124, 3149-3163 (2011).

63. Schertzer, M. et al. Human regulator of telomere elongation helicase 1 (RTEL1) is required for the nuclear and cytoplasmic trafficking of pre-U2 RNA. Nucleic Acids Res. 43, 1834-1847 (2015).

64. Bharti, S. K., Awate, S., Banerjee, T. \& Brosh, R. M. Getting ready for the dance: FANCJ irons out DNA wrinkles. Genes 7, 31 (2016).

65. Neidle, S. Quadruplex nucleic acids as novel therapeutic targets. J. Med. Chem. 59, 5987-6011 (2016).

66. Rodriguez, R. et al. A novel small molecule that alters shelterin integrity and triggers a DNA-damage response at telomeres. J. Am. Chem. Soc. 130, 15758-15759 (2008).

67. Muller, S., Kumari, S., Rodriguez, R. \& Balasubramanian, S. Small-moleculemediated G-quadruplex isolation from human cells. Nat. Chem. 2, 1095-1098 (2010).

68. Sillen, A. \& Engelborghs, Y. The correct use of "average" fluorescence parameters. Photochem. Photobiol. 67, 475-486 (1998).
69. Vysniauskas, A. et al. Exploring viscosity, polarity and temperature sensitivity of BODIPY-based molecular rotors. Phys. Chem. Chem. Phys. 19, 25252-25259 (2017)

70. Warren, S. C. et al. Rapid global fitting of large Fluorescence Lifetime Imaging Microscopy datasets. PLoS ONE 8, e70687 (2013).

\section{Acknowledgements}

The Engineering and Physical Sciences Research Council (EPSRC) of the UK is thanked for financial support including a studentship to B.W.L. and P.C., and a fellowship for M.K.K. (EP/I003983/1). The Royal Society-Newton Fellowships is thanked for financial support to J.G.-G. The Singaporean government is thanked for funding a studentship to A.H.M.L. Imperial College London is thanked for support for this project via the Excellence Fund for Frontier Research. N.M.P. was supported by the European Commission and the production of the Xenopus egg extract was funded by the European Union's Horizon 2020 research and innovation program under the Marie SkłodowskaCurie grant agreement 750035 (ReXeG). Dr Marco Di Antonio is thanked for donating a sample of pyridostatin and useful discussions. Vannier lab's work is supported by the London Institute of Medical Sciences (LMS), which receives its core funding from UKRI (MRC) and by an ERC Starter Grant (637798; MetDNASecStr). Rosa Maria Porreca is funded by ERC Starter Grant (637798; MetDNASecStr). We thank the LMS/NIHR Imperial Biomedical Research Centre Flow Cytometry Facility for support.

\section{Author contributions}

P.A.S., B.W.L., J.G.-G., J.B.V, M.K.K., and R.V. designed the study and co-wrote the paper. P.A.S., B.W.L., J.G.-G., performed experiments and analysed the data. N.M.-P. provided nucleic acid-free extracts and advised on the design of the corresponding experiments. A.L. and D.M. performed the cytotoxicity studies. J.B.E. and P.C. provided advice in the design of the experiments and analysis of the FLIM data. R.M.P. performed DNA damage response staining $(\gamma \mathrm{H} 2 \mathrm{AX})$ and analysis.

\section{Competing interests}

The authors declare no competing interests.

\section{Additional information}

Supplementary information is available for this paper at https://doi.org/10.1038/s41467 020-20414-7.

Correspondence and requests for materials should be addressed to J.B.V., M.K.K. or R.V.

Peer review information Nature Communications thanks the anonymous reviewer(s) for their contribution to the peer review of this work.

Reprints and permission information is available at http://www.nature.com/reprints

Publisher's note Springer Nature remains neutral with regard to jurisdictional claims in published maps and institutional affiliations.

Open Access This article is licensed under a Creative Commons Attribution 4.0 International License, which permits use, sharing, adaptation, distribution and reproduction in any medium or format, as long as you give appropriate credit to the original author(s) and the source, provide a link to the Creative Commons license, and indicate if changes were made. The images or other third party material in this article are included in the article's Creative Commons license, unless indicated otherwise in a credit line to the material. If material is not included in the article's Creative Commons license and your intended use is not permitted by statutory regulation or exceeds the permitted use, you will need to obtain permission directly from the copyright holder. To view a copy of this license, visit http://creativecommons.org/ licenses/by/4.0/

(C) The Author(s) 2021 